\title{
2,3,7,8-Tetrachlorodibenzo-p-dioxin elicited decreases in cobalamin inhibits methylmalonyl-CoA mutase activity redirecting propionyl-CoA metabolism to the $\beta$-oxidation-like pathway resulting in hepatic accumulation of the toxic intermediate acrylyl-CoA
}

Karina Orlowska ${ }^{1,2}$, Russ R. Fling ${ }^{2,3}$, Rance Nault ${ }^{1,2}$ and Tim Zacharewski ${ }^{1,2, *}$

${ }^{1}$ Biochemistry \& Molecular Biology, ${ }^{2}$ Institute for Integrative Toxicology, ${ }^{3}$ Microbiology \& Molecular Genetics, Michigan State University, East Lansing, MI 48824, USA

"Correspondence:

Tim Zacharewski

Michigan State University

Department of Biochemistry \& Molecular Biology

Biochemistry Building

603 Wilson Road

East Lansing, MI 48824

tzachare@msu.edu 


\section{ABSTRACT}

2,3,7,8-Tetrachlorodibenzo-p-dioxin (TCDD) is a persistent environmental contaminant and the prototypical ligand for the aryl hydrocarbon receptor (AhR). AhR mediates the effects of TCDD and related compounds, including the reprograming of intermediate metabolism. Untargeted metabolomics analysis of hepatic extracts prepared from mice orally gavaged with TCDD every 4 days for 28 days identified the dose-dependent induction of acrylyl-CoA, a highly reactive toxic intermediate produced during the metabolism of propionyl-CoA in the cobalamin (Cbl)-independent $\beta$-oxidation-like pathway. Acrylyl-CoA is a biomarker of inborn errors of metabolism associated with propionic and methylmalonic acidemia associated with Cbl deficiency, transport and/or defects in Cbl-dependent methylmalonyl-CoA mutase (MUT). Although TCDD repressed gene expression for both the canonical Cbl-dependent carboxylase and the alternate Cbl-independent $\beta$-oxidationlike pathways, inhibition occurred only at $30 \mu \mathrm{g} / \mathrm{kg}$ TCDD while acrylyl-CoA levels increased at $\sim 3 \mu \mathrm{g} / \mathrm{kg}$. In contrast, TCDD decreased serum Cbl and hepatic cobalt levels at $\sim 3 \mathrm{ug} / \mathrm{kg}$ TCDD consistent with the dosedependent increase in acrylyl-CoA levels. TCDD elicited negligible effects on the expression of genes associated with $\mathrm{Cbl}$ absorption, transport, trafficking and derivatization to 5'-deoxy-adenosylcobalamin (AdoCbl), the required MUT cofactor. In addition, TCDD induced the decarboxylation of cis-aconitate to itaconate by Acod1. Itaconate can then be activated to itaconyl-CoA, a MUT suicide inactivator that forms an adduct with AdoCbl, blocking MUT activity and reducing Cbl levels. Collectively, these results suggest MUT activity was impaired due to $\mathrm{Cbl}$ depletion by TCDD causing propionyl-CoA metabolism to be redirected to the alternate $\mathrm{Cbl}$-independent $\beta$-oxidation-like pathway resulting in hepatic acrylyl-CoA accumulation. 


\section{Introduction}

Adverse effects elicited by exposure to a toxic substance are not only influenced by the dose, route of administration, and duration of exposure but also genetic, epigenetic and other systemic factors. Appropriate responses to the insult are essential to minimize cell damage and ensure survival. Adaptive and adverse effects, such as the induction of cytochrome P450s to metabolize xenobiotics, and metabolic reprogramming, to support of increased glutathione biosynthesis, culminate in an array of apical responses that may lead to inflammation, defense, repair, proliferation and/or cytotoxicity. Genotoxic and non-genotoxic effects trigger the differential expression of genes and modulate enzyme activities that have the potential to qualitatively and quantitatively alter intermediate metabolite profiles. Elucidating this metabolic plasticity is essential for identifying susceptible cell sub-types underlying toxicity and to distinguish adverse from adaptive responses. In addition to discovering strategies to reduce toxicity, understanding the mechanisms involved may reveal novel vulnerabilities that can be exploited as unique therapeutic approaches to treat diseases with similar pathologies.

The progression of simple, reversible hepatic fat accumulation to steatohepatitis with fibrosis describes the typical clinicopathologic spectrum of phenotypes associated with non-alcoholic fatty liver disease (NAFLD). NAFLD is characterized by $>5 \%$ of the cytosolic space within hepatocytes being occupied by lipid droplets in cases where little to no alcohol was consumed and there are no secondary causes such as viral hepatitis, medication, or lipodystrophy (Friedman et al., 2018). Historically, a 'two-hit' hypothesis has been proposed to explain NAFLD development (Day and James, 1998). However, the mechanisms driving progression are poorly understood and likely comprise multiple hits that involve lipotoxicity impacting several pathways (Neuschwander-Tetri, 2010; Tilg and Moschen, 2010). Prevalence of NAFLD cases is projected to increase from $~ 83$ million in 2015 to 101 million by 2030 in the US alone (Estes et al., 2018). Furthermore, NAFLD increases the risk for more complex metabolic disorders including Metabolic Syndrome, cardiovascular disease, diabetes, cirrhosis, and end-stage liver disease (Hardy et al., 2016; Michelotti et al., 2013; Wree et al., 2013). The progression of NAFLD to non-alcoholic steatohepatitis (NASH) is also becoming the leading indication for liver transplantation and the third leading cause of hepatocellular carcinoma in the US with limited treatment options (Budd and Cusi, 2020; Golabi et al., 2018; Polyzos et al., 2020; Sayiner et al., 2018; Wong et al., 2015; Wong and Singal, 2020).

Diet, lifestyle, and genetics are known factors that contribute to NAFLD development and progression. Structurally diverse chemicals and environmental contaminants also induce steatosis, suggesting a possible role in etiology of the disease (Foulds et al., 2017; Rives et al., 2020). For example, pesticides, solvents and their intermediates are the most frequently identified chemicals associated with fatty liver while 2,3,7,8tetrachlorodibenzo-p-dioxin (TCDD) and related compounds exhibit the greatest potency (Al-Eryani et al., 2015; Wahlang et al., 2013). In rodents, TCDD dose-dependently induced micro- and macro-steatosis with marked increases in hepatic unsaturated fatty acids (FAs), triacylglycerols (TAGs), phospholipids and cholesterol esters (CEs) (Fader et al., 2017b; Forgacs et al., 2013; Kania-Korwel et al., 2017; Nault et al., 
2015, 2017; Zhang et al., 2015). TCDD-induced steatosis is caused by increased hepatic uptake of dietary and mobilized peripheral fats, reduced very low density lipoprotein (VLDL) export, and the inhibition of FA oxidation (Cholico et al., 2021; Lakshman et al., 1991; Lee et al., 2010). In humans, exposure to TCDD and related compounds has been associated with dyslipidemia and inflammation (Casals-Casas and Desvergne, 2011; Grun and Blumberg, 2009; Lee et al., 2006; Pelclovä et al., 2006; Taylor et al., 2013; Wahlang et al., 2019; Warner et al., 2013). In epidemiological studies elevated serum cholesterol and TAG levels were reported in exposed workers (Calvert et al., 1996; Martin, 1984; Oliver, 1975; Sweeney et al., 1997), while in utero exposure suggested TCDD increased the risk for Metabolic Syndrome in male offspring (Warner et al., 2019).

TCDD is the prototypical member of a class of persistent environmental contaminants that includes polychlorinated dibenzodioxins (PCDDs), dibenzofurans (PCDFs) and biphenyls (PCBs). Congeners with lateral chlorines induce a plethora of species-, sex-, tissue-, and cell-specific responses (Safe, 1990). TCDD and dioxin-like PCBs are classified as IARC group 1 human carcinogens while evidence for the carcinogenicity of other toxic PCDDs and PCDFs remains equivocal (McGregor et al., 1998; Monographs, 2016, 1997). TCDD and related compounds are non-genotoxic and most, if not all, of their effects are mediated by the aryl hydrocarbon receptor (AhR), a ligand activated basic helix-loop-helix PER-ARNT-SIM transcription factor. Though a number of structurally diverse chemicals, endogenous metabolites, microbial products and natural products can activate the $A h R$, its physiological ligand is unknown. Following ligand binding and the dissociation of chaperone proteins, the activated AhR translocates to the nucleus and dimerizes with the AhR nuclear translocator (ARNT). The heterodimer then binds dioxin response elements (DREs; 5'-GCGTG-3') as well as non-consensus sites throughout the genome that recruit coactivator complexes to the promoter and elicit changes in gene expression (Avilla et al., 2020). AHR-mediated toxicity induced by TCDD and related compounds is considered a result of dysregulated gene expression. However, differential gene expression associated the formation of toxic intermediates from the metabolism of endogenous metabolites has not been fully explored.

The emergence of transcriptomics and metabolomics has provided tools to comprehensively assess the timeand dose-dependent impacts of toxicants on gene expression and intermediate metabolism. Several studies have reported the effects of PCDDs, PCDFs or PCBs on gene expression and/or endogenous metabolite levels in diverse in vivo and in vitro models (Carlson et al., 2009; Fader et al., 2017b, 2017a, 2019; Forgacs et al., 2013; Jennen et al., 2011, 2010; Kopec et al., 2010; Liu et al., 2019; Matsubara et al., 2012; Nault et al., 2015, 2016b, 2017; Rowlands et al., 2011; Ruiz-Aracama et al., 2011; Vezina et al., 2004). In this study, we tested the hypothesis that the dose-dependent accumulation of the toxic metabolite acrylyl-CoA was due to gene repression associated with propionyl-CoA metabolism. The results indicate TCDD dose-dependently reduced cobalamin (Cbl) levels that compromised methylmalonyl-CoA mutase (MUT) activity and blocked the canonical carboxylation metabolism of propionyl-CoA to succinyl-CoA. Consequently, propionyl-CoA was 
redirected to the alternate Cbl-independent $\beta$-oxidation-like pathway resulting in the dose-dependent accumulation of acrylyl-CoA.

\section{MATERIALS AND METHODS}

Animal Treatment - Postnatal day 25 (PND25) male C57BL/6 mice weighing within 10\% of each other were obtained from Charles River Laboratories (Kingston, NY). Mice were housed in Innovive Innocages (San Diego, CA) containing ALPHA-dri bedding (Shepherd Specialty Papers, Chicago, IL) in a $23^{\circ} \mathrm{C}$ environment with 30-40\% humidity and a 12 hr/12 hr light/dark cycle. Aquavive water (Innovive) and Harlan Teklad 22/5 Rodent Diet 8940 (Madison, WI) was provided ad libitum except for a 6hr fast prior to tissue collection. On PND28, mice were orally gavaged at the start of the light cycle (zeitgeber [ZT] 0-1) with $0.1 \mathrm{ml}$ sesame oil vehicle (Sigma-Aldrich, St. Louis, MO) or 0.01, 0.03, 0.1, 0.3, 1, 3, 10, and $30 \mu \mathrm{g} / \mathrm{kg}$ body weight TCDD (AccuStandard, New Haven, CT) every 4 days for 28 days for a total of 7 treatments. The first gavage was administered on day 0 , while the final gavage was on day 24 of the 28 -day study. The doses used compensate for the relatively short study duration compared to lifelong cumulative human exposure from diverse AhR ligands, the bioaccumulative nature of halogenated AhR ligands, and differences in the half-life of TCDD (humans: 1-11 years (Sorg et al., 2009; Wolfe et al., 1994), mice: 8-12d (Gasiewicz et al., 1983). Similar treatment regimens have been used in previous studies (Angrish et al., 2013; Fader et al., 2019; Lee et al., 2010; Matsubara et al., 2012; Nault et al., 2017, 2016a). On day 28, tissue samples were harvested following a $6 \mathrm{hr}$ fast, immediately flash frozen in liquid nitrogen and stored at $-80^{\circ} \mathrm{C}$ until analysis. All animal procedures were in accordance with the Michigan State University (MSU) Institutional Animal Care and Use Committee ethical guidelines and regulations.

\section{Liquid Chromatography Tandem Mass Spectrometry - Samples were extracted using} methanol:water:chloroform as previously described with slight modifications (Fader et al., 2019). Briefly, untargeted extractions were reconstituted with $400 \mu$ tributylamine with no dilutions for analysis. Samples were analyzed on Xevo G2-XS QTOF attached to a Waters UPLC (Waters, Milford, MA) with negative-mode electrospray ionization run in $\mathrm{MS}^{\mathrm{E}}$ continuum mode. $\mathrm{LC}$ phases, gradient rates, and columns were used as previously published (Fader et al., 2019). For untargeted acyl-CoA analysis, MS ${ }^{\mathrm{E}}$ continuum data was processed with Progenesis QI (Waters) to align features, deconvolute peaks, and identify metabolites. Metabolite identifications were scored based on a mass error <12 ppm to Human metabolome Database entries (Wishart et al., 2018), isotopic distribution similarity, and theoretical fragmentation comparisons to $\mathrm{MS}^{\mathrm{E}}$ high-energy mass spectra using the MetFrag option. Raw signals for each compound abundance were normalized to a correction factor calculated using the Progenesis QI median and mean absolute deviation approach. Significance was determined by a one-way ANOVA adjusted for multiple comparisons with a Dunnett's post-hoc test. Raw data is deposited in the NIH Metabolomics Workbench (ST001379).

Gene Expression, ChIP, pDRE and Protein Location Data - Hepatic RNA-seq data sets were previously published (Fader et al., 2019, 2017a; Nault et al., 2018). Genes were considered differentially expressed when $\mid$ fold-change $\mid \geq 1.5$ and posterior probability values $(\mathrm{P} 1(t)) \geq 0.8$ as determined by an empirical Bayes approach 
(Eckel et al., 2004). Hepatic time course (GSE109863), dose response (GSE87519), and diurnal rhythmicity (GSE119780) as well as duodenal (GSE87542), jejunal (GSE90097), proximal (Submitted) and distal ileal (GSE89430) as well as colon (Submitted) sequencing data are available at the Gene Expression Omnibus. Diurnal rhythmicity was determined using JTK_CYCLE as previously described (Fader et al., 2019). AhR ChIPseq (GSE97634) and computationally identified putative dioxin response elements (pDREs, https://doi.org/10.7910/DVN/JASCVZ) data were previously published (Dere et al., 2011; Fader et al., 2017a). Significant AhR ChIP-seq binding used a false discovery rate (FDR) $\leq 0.05$. pDREs were considered functional with a matrix similarity score (MSS) $\geq 0.856$.

Quantitative Real-Time Polymerase Chain Reaction (qRT-PCR) - Expression of Acod1 was determined by qRT-PCR. Total hepatic RNA was reverse transcribed by SuperScript II (Invitrogen, Carlsbad, CA) using oligo dT primer according to the manufacturer's protocol. The qRT-PCR was performed using iQ SYBR Green Supermix (BioRad, Hercules, CA) on a Bio-Rad CFX Connect Real-Time PCR Detection System. Gene expression relative to vehicle control was calculated using the $2^{-\Delta \Delta C T}$ method, where each sample was normalized to the geometric mean of 3 housekeeping genes (Actb, Gapdh, and Hprt). Gene expression data are plotted relative to vehicle control. See Supplementary Table S1 for primer sequences.

Measurement of $\mathrm{Cbl}$ and Cobalt Levels - Serum Cbl levels (vehicle, $1-30 \mu \mathrm{g} / \mathrm{kg}$ TCDD groups) were determined by ELISA using a commercially available kit (Cusabio, Houston, TX) using SpectraMax ABS Plus plate reader (Molecular Devices, San Jose, CA). Cobalt levels were measured in liver extracts (vehicle, 3-30 $\mu \mathrm{g} / \mathrm{kg}$ TCDD groups) using inductively coupled plasma mass spectrometry (ICP-MS) at the MSU Diagnostic Center for Population and Animal Health (DCPAH).

Metagenomic Analysis of Microbial Cbl Metabolism - Cecums from vehicle, 0.3, 3, and $30 \mu \mathrm{g} / \mathrm{kg}$ TCDD treatment groups were used for metagenomic analysis. Genomic DNA was extracted using the FastDNA spin kit for soil (SKU 116560200, MP Biomedicals, Santa Ana, CA) and submitted for quality control, library prep and 150-bp paired-end sequencing at a depth $\geq 136$ million reads using an Illumina NovaSeq 6000 (Novogene, Sacramento, CA). Reads aligning to the C57BL/6 Mus musculus genome (NCBI genome assembly: GRCm38.p6) were identified, flagged and removed using bowtie2 (Langmead et al., 2009), SamTools (Li et al., 2009) and bedtools (Quinlan and Hall, 2010). The HuMaNn3 bioinformatic pipeline (Franzosa et al., 2018) was used with default settings to classify reads to UniRef90 protein ID's using UniProt's UniRef90 protein data base (January, 2019). Reads classified to UniRef90 IDs were mapped to enzyme commission (EC) and PFAM entries using the humann_regroup_table tool. Abundances were normalized to gene copies per million reads using the human_renorm_table tool. Statistical analysis used Maaslin2 (https://github.com/biobakery/Maaslin2) with default settings for normalization (total sum scaling), analysis method (general linear model), and multiple correction adjustment.

\section{RESULTS}

LC-MS/MS analysis - Untargeted metabolomics identified dose-dependent changes in the hepatic levels of intermediates associated with the Cbl-independent $\beta$-oxidation-like metabolism of propionyl-CoA following oral 
gavage with TCDD every 4 days for 28 days (Table 1). Propionyl-, acrylyl- and 3-hydroxypropionyl-CoA were identified based on parent ion mass, isotope similarity, and theoretical fragmentation. Scores $>40$ had features matching parent ion mass and isotope distribution as well as $\mathrm{MS}^{\mathrm{E}}$ fragmentation data matching in silico mass fragmentation, while most metabolite scores averaged $\sim 35$ matching parent ion mass and isotope distribution. The presence of $426.1 \mathrm{~m} / \mathrm{z}$ and $408.0 \mathrm{~m} / \mathrm{z}$ CoA fragment ions observed in the $\mathrm{MS}^{\mathrm{E}}$ fragmentation mass spectra provided further confidence with acyl-CoA identifications. At $30 \mu \mathrm{g} / \mathrm{kg}$ TCDD, hepatic levels of propionyl-CoA were reduced 5.3-fold, while acrylyl- and 3-hydroxypropionyl-CoA were increased 161.7- and 2.8-fold, respectively. This suggests propionyl-CoA was metabolized via the Cbl-independent $\beta$-oxidation-like pathway as opposed to the preferred Cbl-dependent carboxylation pathway (Sato et al., 1999).

Note that the dose range and treatment regimen used in this study resulted in hepatic levels of TCDD that approached steady state while inducing full dose response curves for known AhR target genes (Fig. 1) in the absence of (i) necrosis or apoptosis, (ii) marked increases in serum ALT, (iii) changes in food consumption and (iv) body weight loss >15\% (Fader et al., 2019; Nault et al., 2016a). At 0.01 $\mu \mathrm{g} / \mathrm{kg}$, hepatic levels of TCDD were comparable to control hepatic levels, and to dioxin-like compound levels reported in US, German, Spanish and British serum samples while mid-range doses yielded levels comparable to women from the Seveso Health Study. At $30 \mu \mathrm{g} / \mathrm{kg}$ TCDD, mouse hepatic tissue levels were comparable to serum levels reported in Viktor Yushchenko following intentional poisoning (Alcock et al., 1998; Nault et al., 2016a; Päpke, 1998). Consequently, the metabolomics and gene expression effects, to be discussed in the present study, cannot be attributed to overt toxicity.

Propionyl-CoA metabolism gene expression effects - Fig. 2 summarizes the temporal- and dosedependent effects of TCDD on gene expression associated with propionyl-CoA metabolism. Note that all reported fold-changes discussed in the text were taken from the circadian gene expression data set unless otherwise indicated. Despite similar trends, there may be fold-change discrepancies between the dose response and diurnal rhythmicity studies since the former study was not controlled for sample collection time.

ChIP-seq analysis $2 \mathrm{hrs}$ after a bolus oral gavage of $30 \mu \mathrm{g} / \mathrm{kg}$ TCDD indicates AhR enrichment was not a prerequisite for repression as ethylmalonyl epimerase (Mcee), Mut, 3-hydroxyisobutyryl-CoA hydrolase (Hibch), alcohol dehydrogenase iron containing 1 (Adhfe1) and aldehyde dehydrogenase 6 family member A1 (Aldh6a1) which did not exhibit AhR genomic binding (Fig. 2B, C). Moreover, the effects of TCDD on gene expression associated with both pathways were negligible within $168 \mathrm{hrs}$. TCDD disrupted the oscillating expression pattern of propionyl-CoA carboxylase subunit alpha (Pcca), enoyl-CoA hydratase, short chain 1 (Echs1), Hibch, and Adhfe1 which are diurnally regulated. Although TCDD repressed genes associated with both the Cbl-dependent carboxylation and the Cbl-independent $\beta$-oxidation-like pathways, the doses did not correlate with the dose-dependent increase in acrylyl-CoA levels. Specifically, TCDD-elicited gene repression occurred at $10 \mu \mathrm{g} / \mathrm{kg}$ TCDD or higher while increased acrylyl-CoA levels were observed at dose as low as 3 $\mu \mathrm{g} / \mathrm{kg}$ TCDD. This suggests that the diversion of propionyl-CoA metabolism from the Cbl-dependent 
carboxylation pathway to the Cbl-independent $\beta$-oxidation-like pathway was not due to TCDD-elicited gene repression alone. We next sought to investigate the effects of TCDD on Cbl levels.

Effects on Cbl and cobalt levels - Elevated levels of acrylyl-CoA and 3-hydroxypropionate (3-HP) are not normally detected at appreciable levels in healthy individuals (Matsumoto and Kuhara, 1996). They accumulate following blockage of the canonical Cbl-dependent propionate catabolism pathway as a result of Cbl deficiency or mutations within propionyl-CoA carboxylase or MUT (La Marca et al., 2007). Coincidentally, MUT is only one of two mammalian genes known to be dependent on Cbl for activity. Therefore, we examined the effects of TCDD on the levels of $\mathrm{Cbl}$ and cobalt, the metal ion that occupies the coordinate center of the corrin ring. TCDD dose-dependently reduced total serum $\mathrm{Cbl}$ levels and cobalt levels in hepatic extracts at doses coinciding with acrylyl-CoA increases (Fig. 3). This suggests Cbl deficiency reduced MUT activity resulting in blockage of the canonical carboxylation pathway.

Effects on intestinal $\mathbf{C b l}$ absorption and transport - We next examined the effects of TCDD on the expression of genes associated with intestinal absorption and transport of Cbl. Intrinsic factor (IF, Cblif), a glycoprotein required for intestinal $\mathrm{Cbl}$ absorption, is secreted by parietal cells of the gastric mucosa and therefore was not examined in this study. Cubilin (CUBN) located on the brush border of enterocytes facilitates the endocytic uptake of IF-Cbl complexes. Appreciable levels of Cubn expression were detected in duodenal, jejunal, ileal and colonic intestinal segments (Fig. 4). Cubn was dose-dependently repressed in the duodenum, jejunum, proximal ileum and colon (4.2-, 16.7-, 4.6- and 2.0-fold, respectively), but induced 1.9-fold in the distal ileum. Cbl is then released into the portal circulation in complex with transcobalamin II (TCN2). Repression of Cubn in the duodenum, jejunum, proximal ileum and colon segments suggests intestinal Cbl absorption may be inhibited by TCDD. However, the distal ileum is considered the intestinal segment with the greatest Cbl uptake activity (Schjonsby, 1989).

Cbl bioavailability can also be modulated by gut microbial de novo biosynthesis and utilization as bacterial overgrowth has been shown to cause Cbl deficiencies (Shelton et al., 2018; Singh and Toskes, 2004). Most gut microbiome taxa possess genes encoding $\mathrm{Cbl}$ metabolism associated enzymes. Since previous studies have demonstrated TCDD can alter the gut microbiome, metagenomic analyses of cecal contents from this study were assessed to investigate changes in gut microbial Cbl metabolism (Degnan et al., 2014; Fader et al., 2017b). Gene abundance for Cbl biosynthesis and utilization appeared unaffected except for a modest 1.3-fold repression of precorrin-3 methylase (EC 2.1.1.133), an intermediate step in corrin ring biosynthesis, and a 3fold increase in ABC cobalt transporters (PFAM: PF09819) (Suppl. Fig. 1 and 2). Likewise, TCDD had negligible effects on gut microbial propionate metabolism (Suppl. Table 2). Based on our metagenomics analysis of cecal contents, TCDD elicited negligible effects on microbial Cbl and propionate metabolism.

Effects on hepatic Cbl uptake, metabolism and trafficking - We also examined the effects of TCDD on gene expression associated with hepatic Cbl uptake, metabolism and trafficking. In humans, Cbl in the blood is associated with transcobalamin II (TCN2) or haptocorrin (TCN1) which are internalized by hepatocytes following interaction with the transcobalamin receptor (CD320) or the asialoglycoprotein (ASGR1 and 2), 
respectively, and delivered to lysosomes where TCN2 is degraded and Cbl is released. Tcn2 was repressed 1.5 -fold but only at $30 \mu \mathrm{g} / \mathrm{kg}$ TCDD. TCN1 is not expressed in mice, and therefore the 2.4- and 3.9-fold repression of Asgr1 and 2, respectively, is insignificant in regards to hepatic Cbl uptake (Greibe et al., 2012; Watkins and Rosenblatt, 2011). Released Cbl is exported from the lysosomes via the Lysosome Membrane Chaperone 1 (LMBRD1) where they bind to Metabolism of Cobalamin Associated C (MMACHC) protein for shuttling to cytoplasm methionine synthase (MTR) and mitochondrial MUT (Fig. 5). Additional proteins including Metabolism of Cobalamin Associated A (MMAA) and B (MMAB) convert Cbl to the active AdoCbl required for MUT activity. Overall, TCDD elicited minimal effects on gene expression suggesting hepatic uptake, metabolism and trafficking are not responsible for lower Cbl levels.

Cbl depletion and MUT inhibition - Recent studies show itaconate, an immunomodulatory and antimicrobial metabolite of aconitate produced by aconitate decarboxylase 1 (ACOD1 aka IRG1) in macrophages, can be activated to itaconyl-CoA, a potent suicide inhibitor of MUT (Fig. 6A). Itaconyl-CoA forms an adduct with the 5deoxyadenosyl moiety of AdoCbl disrupting auxiliary repair protein interactions that inactivates AdoCbl, reduces Cbl levels, and effectively blocks MUT activity (Ruetz et al., 2019; Shen et al., 2017). Itaconyl-CoA was detected in liver extracts from TCDD treated mice by untargeted metabolomics with levels dropping 5.3fold at $30 \mu \mathrm{g} / \mathrm{kg}$ TCDD (Table 2). Hepatic Acod1 exhibited time-dependent induction following oral gavage with $30 \mu \mathrm{g} / \mathrm{kg}$ TCDD every 4 days for 28 days in the absence of AhR genomic enrichment at $2 \mathrm{hrs}$. Time-dependent Acod1 induction coincided with increased ALT levels (Boverhof et al., 2005) and the time-dependent increase in macrophages markers, Adgre1, Cd5I, and Csfr1 (2.3-, 1.9-, and 1.9-fold, respectively) at 168 hrs after a single bolus oral gavage of $30 \mu \mathrm{g} / \mathrm{kg}$ TCDD (Fig. 6B, K). Adgre1 and Cd5/ did not exhibit AhR genomic enrichment at $2 \mathrm{hrs}$ suggesting increases were due to macrophages recruitment and/or proliferation while Csf1r induction may involve the AhR. The low number of macrophages within control livers confound distinguishing Adgre1, Cd5I, and Csfr1 increases due to induction by TCDD from increased macrophage levels following infiltration into the liver and/or macrophages proliferation (Nault et al., 2020). TCDD also dosedependently induced Acod1 (Fig. 6C). Discrepancies in the fold-changes between the time course, dose response and circadian studies are consistent with the erratic rhythmic expression of Acod1 over the $24 \mathrm{hr}$ time period (Fig 6D) (Fader et al., 2017b). The catabolic itaconyl-CoA metabolite, citramalyl-CoA, was also detected but exhibited a dose-dependent decrease in hepatic extracts suggesting itaconyl-CoA metabolism was diverted given the negligible effects on Auh and Clybl (Table 2, Fig. 6A, H, I). Collectively, these observations suggest itaconate was produced following the induction of Acod1 in activated macrophages following TCDD treatment, and therefore may contribute to the inactivation of MUT.

\section{DISCUSSION}

In this study, metabolomics and gene expression datasets were integrated to examine the dose-dependent induction of acrylyl-CoA levels in liver extracts from mice orally gavaged with TCDD every 4 days for 28 days. Elevated levels of acrylyl-CoA and 3-HP, short chain intermediates in the catabolism of propionyl-CoA to acetyl-CoA, are typically used as indicators of inborn metabolic disorders associated with propionic- and methylmalonic acidemia (Schwab et al., 2006), although low levels of 3-HP have also been detected in healthy 
individuals (Bouatra et al., 2013; Guneral and Bachmann, 1994). Moreover, 3-HP is an intermediate in the $\beta$ oxidation-like metabolism of propionyl-CoA in some Cbl-independent plants, insects and bacteria (Halarnkar and Blomquist, 1989; Otzen et al., 2014). This led us to investigate TCDD-elicited metabolic reprogramming that redirected propionate metabolism from the canonical Cbl-dependent carboxylation pathway producing succinyl-CoA to the alternative Cbl-independent $\beta$-oxidation-like pathway that involved acrylyl-CoA and 3-HP as intermediates.

Propionyl-CoA is the byproduct of a number of reactions including the oxidative metabolism of odd numbered carbon fatty acids as well as the catabolism of several amino acids (i.e., methionine, threonine, isoleucine and valine). However, the most likely source of hepatic propionyl-CoA following TCDD treatment is the shortening of C27-bile acid intermediates to mature C24-bile acids (Antonenkov et al., 1997) since TCDD dosedependently increased total bile acids in the liver and serum (Fader et al., 2017b), inhibited fatty acid oxidation (Cholico et al., 2021; Lakshman et al., 1991; Lee et al., 2010), and had negligible effects on microbial gene expression associated with gut propionate biosynthesis. Acyl-CoA dehydrogenases have extremely low activity towards propionyl-CoA as a substrate. Therefore, propionyl-CoA is preferentially metabolized by the Cbldependent carboxylation pathway where it is first carboxylated by propionyl-CoA carboxylase (PCC) to (S)methylmalonyl-CoA and then converted to (R)-methylmalonyl-CoA by methylmalonyl-CoA epimerase (MCEE). Finally, the (R)-methylmalonyl-CoA intermediate undergoes rearrangement by Cbl-dependent MUT to produce the anaplerotic precursor, succinyl-CoA, which is subsequently fed into the tricarboxylic acid cycle. Pcca, Pccb, Mcee and Mut were all repressed by TCDD, but only at doses of $30 \mu \mathrm{g} / \mathrm{kg}$ TCDD while acrylyl-CoA was detected following treatment with $3 \mu \mathrm{g} / \mathrm{kg}$ TCDD suggesting inhibition of gene expression associated with the Cbl-dependent carboxylation pathway does not adequately explain the dose-dependent increase in hepatic acrylyl-CoA levels.

MUT is one of two mammalian enzymes that uses a Cbl derivative as a cofactor, the other being MTR. More specifically, MUT requires AdoCbl for the rearrangement of $(R)$-methylmalonyl-CoA to succinyl-CoA while MTR uses methylcobalamin ( $\mathrm{MeCbl}$ ) for the methylation of homocysteine to produce methionine (Banerjee et al., 2009). Cbl is considered a rare cofactor with levels ranging between 30-700 nM in humans (Hsu, 1966). It is only synthesized by microorganisms with absorption in humans limited to the distal ileum (Schjonsby, 1989). Given low levels of $\mathrm{Cbl}$ and potential reactivity in three biologically relevant oxidation states, a complex escort system comprising transporters and chaperones has evolved to ensure delivery to mitochondrial MUT and cytosolic MTR. At least nine genes are dedicated to the absorption, transport, assimilation, derivatization and trafficking of $\mathrm{Cbl}$ and its derivatives (Banerjee et al., 2009). Inborn metabolic disorders as well as intestinal bacterial overgrowth that reduce $\mathrm{Cbl}$ levels or disrupt delivery have been implicated in methylmalonic aciduria and/or hyperhomocysteinemia (Singh and Toskes, 2004; Watkins et al., 2011).

TCDD had minimal effects on gene expression associated with Cbl absorption, transport, assimilation, derivatization and trafficking, except for Cubn, the membrane receptor responsible for the endocytic uptake of IF-Cbl complexes expressed at the apical pole of enterocytes. Cubn in the duodenum, jejunum, proximal ileum and colon was dose-dependently repressed between 3 and $30 \mu \mathrm{g} / \mathrm{kg}$ TCDD coinciding with the dose- 
dependent decreases in hepatic Cbl levels. However, Cbl absorption in humans has been attributed to the distal ileum (Kozyraki and Cases, 2013; Schjonsby, 1989). Moreover, the mouse distal ileum had the highest Cubn expression levels and was induced by TCDD in the distal ileum segment compared to the other intestinal segments. Although enticing to suggest TCDD-elicited repression of Cubn in the duodenum, jejunum, proximal ileum and colon was responsible for the dose-dependent decrease in hepatic Cbl levels, the induction and overall higher basal expression levels of Cubn in the ileum, the primary site of Cbl absorption, implies otherwise.

Other potential mechanisms for lower hepatic $\mathrm{Cbl}$ levels also warrant consideration. This includes the effects of TCDD on gastric mucosa parietal cell expression of IF (Watkins et al., 2011) and the possibility of malabsorption due to intestinal bacterial overgrowth (Schjonsby, 1989). More recently, decreases in Cbl levels have been linked to itaconate, a cis-aconitate metabolite produced in large quantities by activated macrophages (Ruetz et al., 2019; Shen et al., 2017). Itaconate possesses anti-inflammatory properties that block pro-inflammatory cytokine release, inhibit reactive oxygen species (ROS) production, activate the master antioxidant regulator NRF2, and induce the anti-inflammatory transcription factor, ATF3 (Hooftman and O'Neill, 2019; O'Neill and Artyomov, 2019). The induction of Acod1, which converts cis-aconitate to itaconate, coincides with the increased expression of macrophages markers and dose-dependent decrease in hepatic Cbl levels. ACOD1 is also transcriptionally and post-transcriptionally regulated in response to LPS and IFN (O'Neill and Artyomov, 2019; Strelko et al., 2011). Consequently, the bacterial overgrowth and leaky gut caused by TCDD (Fader et al., 2017b) are consistent with induction by LPS given the absence of AhR enrichment within the Acod1 loci. However, the ability of itaconate secreted by macrophages to be absorbed by adjacent cells and cause intracellular effects is controversial (Zaslona and O'Neill, 2020). Itaconate can be activated to itaconyl-CoA, and subsequently metabolized to citramalyl-CoA, although there may be other sources of these intermediates (Shen et al., 2017). Furthermore, a recent study showed that itaconyl-CoA is a suicide inactivator that not only inhibits MUT activity by forming a stable adduct with the 5'-deoxyadenosyl moiety of AdoCbl but also reduces Cbl levels (Ruetz et al., 2019). Additional studies are needed to determine which mechanism is responsible for decreased Cbl levels.

With inhibition of the preferred Cbl-dependent carboxylation pathway, propionyl-CoA is redirected to the less thermodynamically favorable Cbl-independent $\beta$-oxidation-like pathway as indicated by the marked dosedependent increase in the toxic intermediate, acrylyl-CoA. Interestingly, the dose-dependent inhibition of $\beta$ oxidation by TCDD caused a marked dose-dependent increase in other enoyl-CoA species including octenoylCoA that paralleled the increase in acrylyl-CoA in liver extracts (Cholico et al., 2021). Subsequent metabolism of enoyl-CoA species, including acrylyl-CoA, involves a hydration reaction. Trifunctional protein (MTP) is a multi-subunit enzyme that carries out enoyl-CoA hydratase, hydroxyacyl-CoA dehydrogenase, and 3ketothiolase activities in the $\beta$-oxidation of straight chain fatty acids. The HADHA enoyl-CoA hydratase subunit of MTP prefers longer chain (C12-16) enoyl substrates with minimal activity towards short chain (C4) enoylCoAs (Eaton et al., 2000). In contrast, the ECHS1 subunit prefers shorter chain (C4) enoyl-CoAs with diminishing binding affinity as enoyl-CoAs approach C10 in length (Burgin and McKenzie, 2020). Moreover, 
acrylyl-CoA is reported to be efficiently hydrated to 3-HP-CoA by ECHS1 (Shimomura et al., 1994). Our recent studies showed TCDD increased octenoyl-CoA levels and that octenoyl-CoA inhibited the hydration of crotonyl-CoA, a C4 enoyl-CoA and the preferred substrate of ECHS1 (Cholico et al., 2021; Eaton et al., 2000). Collectively, the data suggest ECHS1 activity is inhibited by octenoyl-CoA resulting in the accumulation of acrylyl-CoA. Inborn metabolic disorders causing a deficiency in ECHS1 activity have also been linked to the urinary accumulation of acrylyl-CoA in infants with evidence of more severe pathologies unmasked following palmitate loading (Haack et al., 2015; Peters et al., 2015). Acrylyl-CoA is a highly reactive intermediate that readily undergoes addition reactions with sulphhydryl groups to disrupt protein structure and activity (Shimomura et al., 1994). Coincidentally, hepatic $\beta$-oxidation occurs predominantly in the portal region, the zone first exhibiting lipid accumulation and immune cell infiltration following dose-dependent TCDD treatment (Boverhof et al., 2005).

In summary, we propose the intersection of multiple effects elicited by TCDD result in the dose-dependent increase in acrylyl-CoA levels. The accumulation of triacylgycerols, FAs, cholesterol, cholesterol esters and phospholipids is first observed as macro- and micro-steatosis following TCDD treatment (Boverhof et al., 2005; Nault et al., 2015). Fatty liver in combination with increased ROS levels from TCDD-induced oxidoreductase activities such as CYP1A1, XDH/XO and AOX1 cause oxidative stress and lipotoxicity, resulting in the second histopathological response reported, namely tissue damage, and inflammation. This is accompanied by enterohepatic circulation disruption that not only increased levels of bile acid levels and its propionyl-CoA byproduct, but is accompanied by gut bacteria overgrowth, reduced intestinal motility, and increased intestinal permeability that likely increased serum levels of LPS and cytokines including IFN $\square$ (Fader et al., 2017b; Nault et al., 2016a). Serum LPS and IFN $\square$ would further increase hepatic oxidative stress, activate infiltrating macrophages and induce ACOD1 activity (Strelko et al., 2011). Activated macrophages are reported to produce millimolar levels of itaconate with extracellular itaconate taken up and converted to itaconyl-CoA, the suicide MUT inhibitor (Michelucci et al., 2013). Blockage of MUT activity redirects propionyl-CoA towards the less favorable Cbl-independent $\beta$-oxidation-like pathway where propionyl-CoA is oxidized to acrylyl-CoA. Normally, acrylyl-CoA would be hydrated to 3-HP but ECHS1 activity is blocked by accumulating octenoyl-CoA (Cholico et al., 2021). Consequently, acrylyl-CoA as well as other toxic metabolites produced as a result of aberrant metabolic reprograming may contribute to the periportal toxicity of TCDD. Overall, the metabolic changes induced by TCDD are consistent with the progression of steatosis to steatohepatitis with fibrosis. Additional studies are needed to further elucidate the mechanisms of Cbl depletion and to determine their relevance in human models.

\section{ACKOWLEDGEMENTS}

This project was supported by the National Institute of Environmental Health Sciences Superfund Research Program [NIEHS SRP P42ES004911] and R01ES029541 to TRZ. TRZ is partially supported by AgBioResearch at Michigan State University. RRF was supported by NIEHS Multidisciplinary Training in Environmental Toxicology [T32ES007255]. 


\section{CONTRIBUTIONS}

RRF, RN and TRZ designed the study. RRF and RN performed the animal work. KO, RRF and RN performed the experiments. RRF developed the LC-MS method used for the untargeted metabolomics analysis and was responsible for the metagenomics analysis. KO and RRF prepared the figures and tables. KO, RRF and TZ wrote the manuscript. All authors edited and reviewed the manuscript.

\section{REFERENCES}

Al-Eryani, L., Wahlang, B., Falkner, K.C., Guardiola, J.J., Clair, H.B., Prough, R.A., Cave, M., 2015. Identification of Environmental Chemicals Associated with the Development of Toxicant-associated Fatty Liver Disease in Rodents. Toxicol. Pathol. 43, 482-497. https://doi.org/10.1177/0192623314549960

Alcock, R.E., Behnisch, P.A., Jones, K.C., Hagenmaier, H., 1998. Dioxin-Like PCBs in the Environment Human Exposure and the Significance of Sources. Chemosphere 37, 1457-1472. https://doi.org/10.1016/S0045-6535(99)00137-X

Angrish, M.M., Dominici, C.Y., Zacharewski, T.R., 2013. TCDD-Elicited effects on liver, serum, and adipose lipid composition in C57BL/6 mice. Toxicol. Sci. 131, 108-115. https://doi.org/10.1093/toxsci/kfs277

Antonenkov, V.D., Van Veldhoven, P.P., Waelkens, E., Mannaerts, G.P., 1997. Substrate specificities of 3oxoacyl-CoA thiolase a and sterol carrier protein 2/3-oxoacyl-coa thiolase purified from normal rat liver peroxisomes. Sterol carrier protein 2/3-oxoacyl-CoA thiolase is involved in the metabolism of 2-methylbranched fatty ac. J. Biol. Chem. 272, 26023-26031. https://doi.org/10.1074/jbc.272.41.26023

Avilla, M.N., Malecki, K.M.C., Hahn, M.E., Wilson, R.H., Bradfield, C.A., 2020. The Ah Receptor: Adaptive Metabolism, Ligand Diversity, and the Xenokine Model. Chem. Res. Toxicol. 33, 860-879. https://doi.org/10.1021/acs.chemrestox.9b00476

Banerjee, R., Gherasim, C., Padovani, D., 2009. The tinker, tailor, soldier in intracellular B12 trafficking. Curr. Opin. Chem. Biol. 13, 484-491. https://doi.org/10.1016/j.cbpa.2009.07.007.The

Bouatra, S., Aziat, F., Mandal, R., Guo, A.C., Wilson, M.R., Knox, C., Bjorndahl, T.C., Krishnamurthy, R., Saleem, F., Liu, P., Dame, Z.T., Poelzer, J., Huynh, J., Yallou, F.S., Psychogios, N., Dong, E., Bogumil, R., Roehring, C., Wishart, D.S., 2013. The Human Urine Metabolome. PLoS One 8. https://doi.org/10.1371/journal.pone.0073076

Boverhof, D.R., Burgoon, L.D., Tashiro, C., Chittim, B., Harkema, J.R., Jump, D.B., Zacharewski, T.R., 2005. Temporal and dose-dependent hepatic gene expression patterns in mice provide new insights into TCDDmediated hepatotoxicity. Toxicol. Sci. 85, 1048-1063. https://doi.org/10.1093/toxsci/kfi162

Budd, J., Cusi, K., 2020. Nonalcoholic Fatty Liver Disease: What Does the Primary Care Physician Need to Know? Am. J. Med. 133, 536-543. https://doi.org/10.1016/j.amjmed.2020.01.007

Burgin, H.J., McKenzie, M., 2020. Understanding the role of OXPHOS dysfunction in the pathogenesis of ECHS1 deficiency. FEBS Lett. 594, 590-610. https://doi.org/10.1002/1873-3468.13735

Calvert, G.M., Wille, K.K., Sweeney, M.H., Halperin, W.E., 1996. Evaluation of serum lipid concentrations among U.S. Workers exposed to 2,3,7,8-tetrachlorodibenzo-p-dioxin. Arch. Environ. Health 51, $100-107$. https://doi.org/10.1080/00039896.1996.9936001

Carlson, E.A., Roy, N.K., Wirgin, I.I., 2009. Microarray analysis of polychlorinated biphenyl mixture-induced changes in gene expression among atlantic tomcod populations displaying differential sensitivity to halogenated aromatic hydrocarbons. Environ. Toxicol. Chem. 28, 759-771. https://doi.org/10.1897/08195R.1

Casals-Casas, C., Desvergne, B., 2011. Endocrine disruptors: From endocrine to metabolic disruption. Annu. Rev. Physiol. 73, 135-162. https://doi.org/10.1146/annurev-physiol-012110-142200 
Cholico, G.N., Fling, R.R., Zacharewski, N.A., Fader, K.A., Nault, R., Zacharewski, T., 2021. Thioesterase induction by 2,3,7,8-tetrachlorodibenzo-p-dioxin results in a futile cycle that inhibits hepatic $\beta$-oxidation. bioRxiv doi: https. https://doi.org/10.1101/2021.01.21.427582

Day, C.P., James, O.F.W., 1998. Steatohepatitis: A tale of two "Hits"? Gastroenterology 114, $842-845$. https://doi.org/10.1016/S0016-5085(98)70599-2

Degnan, P.H., Taga, M.E., Goodman, A.L., 2014. Vitamin B12 as a modulator of gut microbial ecology. Cell Metab. 20, 769-778. https://doi.org/10.1016/j.cmet.2014.10.002

Dere, E., Lo, R., Celius, T., Matthews, J., Zacharewski, T.R., 2011. Integration of Genome-Wide Computation DRE Search, AhR ChIP-chip and Gene Expression Analyses of TCDD-Elicited Responses in the Mouse Liver. BMC Genomics 12, 365. https://doi.org/10.1186/1471-2164-12-365

Eaton, S., Bursby, T., Middleton, B., Pourfarzam, M., Mills, K., Johnson, W., Barlett, K., 2000. The mitochondrial trifunctional protein: centre of a $\beta$-oxidation metabolon? Biochem. Soc. Trans. 28, 177-182.

Eckel, J.E., Gennings, C., Chinchilli, V.M., Burgoon, L.D., Zacharewski, T.R., 2004. Empirical bayes gene screening tool for time-course or dose-response microarray data. J. Biopharm. Stat. 14, 647-670. https://doi.org/10.1081/BIP-200025656

Estes, C., Razavi, H., Loomba, R., Younossi, Z., Sanyal, A.J., 2018. Modeling the epidemic of nonalcoholic fatty liver disease demonstrates an exponential increase in burden of disease. Hepatology 67, 123-133. https://doi.org/10.1002/hep.29466

Fader, K.A., Nault, R., Doskey, C.M., Fling, R.R., Zacharewski, T.R., 2019. 2,3,7,8-Tetrachlorodibenzo-p-dioxin abolishes circadian regulation of hepatic metabolic activity in mice. Sci. Rep. 9, 1-18. https://doi.org/10.1038/s41598-019-42760-3

Fader, K.A., Nault, R., Kirby, M.P., Markous, G., Matthews, J., Zacharewski, T.R., 2017a. Convergence of hepcidin deficiency, systemic iron overloading, heme accumulation, and REV-ERBa/ $\beta$ activation in aryl hydrocarbon receptor-elicited hepatotoxicity. Toxicol. Appl. Pharmacol. 321, 1-17. https://doi.org/10.1016/j.taap.2017.02.006

Fader, K.A., Nault, R., Zhang, C., Kumagai, K., Harkema, J.R., Zacharewski, T.R., 2017b. 2,3,7,8Tetrachlorodibenzo-p-dioxin (TCDD)-elicited effects on bile acid homeostasis: Alterations in biosynthesis, enterohepatic circulation, and microbial metabolism. Sci. Rep. 7, 1-17. https://doi.org/10.1038/s41598017-05656-8

Forgacs, A.L., Dere, E., Angrish, M.M., Zacharewski, T.R., 2013. Comparative analysis of temporal and dosedependent TCDD-elicited gene expression in human, mouse, and rat primary hepatocytes. Toxicol. Sci. 133, 54-66. https://doi.org/10.1093/toxsci/kft028

Foulds, C.E., Trevino, L.S., York, B., Walker, C.L., 2017. Endocrine-disrupting chemicals and fatty liver disease. Nat. Rev. Endocrinol. 13, 445-457. https://doi.org/10.1038/nrendo.2017.42.Endocrine-disrupting

Franzosa, E.A., Mclver, L.J., Rahnavard, G., Thompson, L.R., Schirmer, M., Weingart, G., Lipson, K.S., Knight, R., Caporaso, J.G., Segata, N., Huttenhower, C., 2018. Species-level functional profiling of metagenomes and metatranscriptomes. Nat. Methods 15, 962-968. https://doi.org/10.1038/s41592-018-0176-y

Friedman, S.L., Neuschwander-Tetri, B.A., Rinella, M., Sanyal, A.J., 2018. Mechanisms of NAFLD development and therapeutic strategies, Nature Medicine. https://doi.org/10.1038/s41591-018-0104-9

Gasiewicz, T., Geiger, L., Rucci, G., Neal, R., 1983. Distribution, excretion, and metabolism of 2,3,7,8tetrachlorodibenzo-p-dioxin in C57BL/6J, DBA/2J, and B6D2F1/J mice. Drug Metab Dispos 11(5), 397403.

Golabi, P., Otgonsuren, M., De Avila, L., Sayiner, M., Rafiq, N., Younossi, Z.M., 2018. Components of metabolic syndrome increase the risk of mortality in nonalcoholic fatty liver disease (NAFLD). Med. (United States) 97, 18-23. https://doi.org/10.1097/MD.0000000000010214

Greibe, E., Fedosov, S., Nexo, E., 2012. The cobalamin-binding protein in zebrafish is an intermediate 
bioRxiv preprint doi: $h t t p s: / / d o i . o r g / 10.1101 / 2021.03 .24 .436837$ t this version posted March 25,2021 . The copyright holder for this preprint (which was not certified by peer review) is the author/funder, who has granted bioRxiv a license to display the preprint in perpetuity. It is made available under aCC-BY-ND 4.0 International license.

between the three cobalamin-binding proteins in human. PLoS One 7. https://doi.org/10.1371/journal.pone.0035660

Grun, F., Blumberg, B., 2009. Endocrine disruptors as obesogens. Mol. Cell. Endocrinol. 304, $19-29$. https://doi.org/10.1007/978-3-319-68192-4_14

Guneral, F., Bachmann, C., 1994. Age-related reference values for urinary organic acids in a healthy Turkish pediatric population. Clin. Chem. 40, 862-868. https://doi.org/10.1093/clinchem/40.6.862

Haack, T.B., Jackson, C.B., Murayama, K., Kremer, L.S., Schaller, A., Kotzaeridou, U., de Vries, M.C., Schottmann, G., Santra, S., Büchner, B., Wieland, T., Graf, E., Freisinger, P., Eggimann, S., Ohtake, A., Okazaki, Y., Kohda, M., Kishita, Y., Tokuzawa, Y., Sauer, S., Memari, Y., Kolb-Kokocinski, A., Durbin, R., Hasselmann, O., Cremer, K., Albrecht, B., Wieczorek, D., Engels, H., Hahn, D., Zink, A.M., Alston, C.L., Taylor, R.W., Rodenburg, R.J., Trollmann, R., Sperl, W., Strom, T.M., Hoffmann, G.F., Mayr, J.A., Meitinger, T., Bolognini, R., Schuelke, M., Nuoffer, J.M., Kölker, S., Prokisch, H., Klopstock, T., 2015. Deficiency of ECHS1 causes mitochondrial encephalopathy with cardiac involvement. Ann. Clin. Transl. Neurol. 492-509. https://doi.org/10.1002/acn3.189

Halarnkar, P.P., Blomquist, G.J., 1989. Comparative aspects of propionate metabolism. Comp. Biochem. Physiol. -- Part B Biochem. 92, 227-231. https://doi.org/10.1016/0305-0491(89)90270-8

Hardy, T., Oakley, F., Anstee, Q.M., Day, C.P., 2016. Nonalcoholic Fatty Liver Disease: Pathogenesis and Disease Spectrum. Annu. Rev. Pathol. Mech. Dis. 11, 451-496. https://doi.org/10.1146/annurev-pathol012615-044224

Hooftman, A., O'Neill, L.A.J., 2019. The Immunomodulatory Potential of the Metabolite Itaconate. Trends Immunol. 40, 687-698. https://doi.org/10.1016/j.it.2019.05.007

Hsu, J.M., 1966. Vitamin B12 Concentrations in Human Tissues. Nature 210, 1264-1265.

Jennen, D., Ruiz-Aracama, A., Magkoufopoulou, C., Peijnenburg, A., Lommen, A., van Delft, J., Kleinjans, J., 2011. Integrating transcriptomics and metabonomics to unravel modes-of-action of 2,3,7,8tetrachlorodibenzo-p-dioxin (TCDD) in HepG2 cells. BMC Syst. Biol. 5, 139. https://doi.org/10.1186/17520509-5-139

Jennen, D.G.J., Magkoufopoulou, C., Ketelslegers, H.B., Herwijnen, M.H.M. Van, Kleinjans, J.C.S., Delft, J.H.M. Van, 2010. Comparison of HepG2 and HepaRG by Whole-Genome Gene Expression Analysis for the Purpose of Chemical Hazard Identification 115, 66-79. https://doi.org/10.1093/toxsci/kfq026

Kania-Korwel, I., Wu, X., Wang, K., Lehmler, H.J., 2017. Identification of lipidomic markers of chronic 3,3',4,4',5-pentachlorobiphenyl (PCB 126) exposure in the male rat liver. Toxicology 390, 124-134. https://doi.org/10.1016/j.tox.2017.09.005

Kopec, A.K., Burgoon, L.D., Ibrahim-Aibo, D., Burg, A.R., Lee, A.W., Tashiro, C., Potter, D., Sharratt, B., Harkema, J.R., Rowlands, J.C., Budinsky, R.A., Zacharewski, T.R., 2010. Automated dose-response analysis and comparative toxicogenomic evaluation of the hepatic effects elicited by TCDD, TCDF, and PCB126 in C57bl/6 mice. Toxicol. Sci. 118, 286-297. https://doi.org/10.1093/toxsci/kfq236

Kozyraki, R., Cases, O., 2013. Vitamin B12 absorption: Mammalian physiology and acquired and inherited disorders. Biochimie 95, 1002-1007. https://doi.org/10.1016/j.biochi.2012.11.004

La Marca, G., Malvagia, S., Pasquini, E., Innocenti, M., Donati, M.A., Zammarchi, E., 2007. Rapid 2nd-tier test for measurement of 3-OH-propionic and methylmalonic acids on dried blood spots: Reducing the falsepositive rate for propionylcarnitine during expanded newborn screening by liquid chromatography-tandem mass spectrometry. Clin. Chem. 53, 1364-1369. https://doi.org/10.1373/clinchem.2007.087775

Lakshman, M.R., Ghosh, P., Chirtel, S.J., 1991. Mechanism of Action of 2,3,7,8-.Tetrachlorodibenzo-p-Dioxin Intermediary Metabolism in the Rat. J. Pharmacol. Exp. Ther. 258. https://doi.org/10.1016/00243205(67)90024-0

Langmead, B., Trapnell, C., Pop, M., Salzberg, S.L., 2009. Ultrafast and memory-efficient alignment of short DNA sequences to the human genome. Genome Biol. 10. https://doi.org/10.1186/gb-2009-10-3-r25 
Lee, C.C., Yao, Y.J., Chen, H.L., Guo, Y.L., Su, H.J., 2006. Fatty liver and hepatic function for residents with markedly high serum PCDD/Fs levels in Taiwan. J. Toxicol. Environ. Heal. - Part A 69, 367-380. https://doi.org/10.1080/15287390500244972

Lee, J.H., Wada, T., Febbraio, M., He, Ji., Matsubara, T., Lee, M.J., Gonzalez, F.J., Xie, W., 2010. A novel role for the dioxin receptor in fatty acid metabolism and hepatic steatosis. Gastroenterology 139, 653-663. https://doi.org/10.1053/j.gastro.2010.03.033.A

Li, H., Handsaker, B., Wysoker, A., Fennell, T., Ruan, J., Homer, N., Marth, G., Abecasis, G., Durbin, R., 2009. The Sequence Alignment/Map format and SAMtools. Bioinformatics 25, 2078-2079. https://doi.org/10.1093/bioinformatics/btp352

Liu, Q., Cai, J., Nichols, R.G., Tian, Y., Zhang, J., Smith, P.B., Wang, Y., Yan, C., Patterson, A., 2019. A Quantitative HILIC-MS/MS Assay of the Metabolic Response of Huh-7 Cells Exposed to 2,3,7,8Tetrachlorodibenzo-p-Dibenzo-p-Dioxin. Metabolites 9. https://doi.org/10.3390/metabo9060118

Martin, J. V., 1984. Lipid abnormalities in workers exposed to dioxin. Br. J. Ind. Med. 41, $254-256$. https://doi.org/10.1136/oem.41.2.254

Matsubara, T., Tanaka, N., Krausz, K.W., Manna, S.K., Kang, D.W., Anderson, E.R., Luecke, H., Patterson, A.D., Shah, Y.M., Gonzalez, F.J., 2012. Metabolomics identifies an inflammatory cascade involved in dioxin- and diet-induced steatohepatitis. Cell Metab. 16, 634-644. https://doi.org/10.1016/j.cmet.2012.10.006.Metabolomics

Matsumoto, I., Kuhara, T., 1996. A new chemical diagnostic method for inborn errors of metabolism by mass spectrometry - rapid, practical, and simultaneous urinary metabolites analysis. Mass Spectrom. Rev. 15, 43-57.

McGregor, D.B., Partensky, C., Wilbourn, J., Rice, J.M., 1998. An IARC evaluation of polychlorinated dibenzop-dioxins and polychlorinated dibenzofurans as risk factors in human carcinogenesis. Environ. Health Perspect. 106, 755-760. https://doi.org/10.1289/ehp.98106755

Michelotti, G.A., Machado, M. V., Diehl, A.M., 2013. NAFLD, NASH and liver cancer. Nat. Rev. Gastroenterol. Hepatol. 10, 656-665. https://doi.org/10.1038/nrgastro.2013.183

Michelucci, A., Cordes, T., Ghelfi, J., Pailot, A., Reiling, N., Goldmann, O., Binz, T., Wegner, A., Tallam, A., Rausell, A., Buttini, M., Linster, C.L., Medina, E., Balling, R., Hiller, K., 2013. Immune-responsive gene 1 protein links metabolism to immunity by catalyzing itaconic acid production. Proc. Natl. Acad. Sci. U. S. A. 110, 7820-7825. https://doi.org/10.1073/pnas.1218599110

Monographs, I., 2016. Polychlorinated Biphenyls and Polybrominated Biphenyls. IARC Monogr. Eval. Carcinog. risks to humans 107, 9-500.

Monographs, I., 1997. Polichlorinated dibenzo-papa-dioxins and polichlorinated dibenzofurans. IARC Monogr. Eval. Carcinog. risks to humans 69.

Nault, R., Colbry, D., Brandenberger, C., Harkema, J.R., Zacharewski, T.R., 2015. Development of a Computational High-Throughput Tool for the Quantitative Examination of Dose-Dependent Histological Features. Toxicol. Pathol. 43, 366-375. https://doi.org/10.1177/0192623314544379

Nault, R., Doskey, C.M., Fader, K.A., Rockwell, C.E., Zacharewski, T., 2018. Comparison of hepatic NRF2 and aryl hydrocarbon receptor binding in 2,3,7,8-tetrachlorodibenzo-p-dioxin-treated mice demonstrates NRF2-independent PKM2 induction. Mol. Pharmacol. 94, 876-884. https://doi.org/10.1124/mol.118.112144

Nault, R., Fader, K.A., Ammendolia, D.A., Dornbos, P., Potter, D., Sharratt, B., Kumagai, K., Harkema, J.R., Lunt, S.Y., Matthews, J., Zacharewski, T., 2016a. Dose-dependent metabolic reprogramming and differential gene expression in TCDD-elicited hepatic fibrosis. Toxicol. Sci. 154, $253-266$. https://doi.org/10.1093/toxsci/kfw163

Nault, R., Fader, K.A., Bhattacharya, S., Zacharewski, T.R., 2020. Single-Nuclei RNA Sequencing Assessment of the Hepatic Effects of 2,3,7,8-Tetrachlorodibenzo-p-dioxin. Cell. Mol. Gastroenterol. Hepatol. 11, 147- 
bioRxiv preprint doi: $\mathrm{https}$ //doi.org/10.1101/2021.03.24.436837; this version posted March 25, 2021. The copyright holder for this preprint (which was not certified by peer review) is the author/funder, who has granted bioRxiv a license to display the preprint in perpetuity. It is made available under aCC-BY-ND 4.0 International license.

159. https://doi.org/10.1016/j.jcmgh.2020.07.012

Nault, R., Fader, K.A., Kopec, A.K., Harkema, J.R., Zacharewski, T.R., Luyendyk, J.P., 2016b. Coagulationdriven hepatic fibrosis requires protease activated receptor-1 (PAR-1) in a mouse model of TCDD-elicited steatohepatitis. Toxicol. Sci. 154, 381-391. https://doi.org/10.1093/TOXSCI/KFW175

Nault, R., Fader, K.A., Lydic, T.A., Zacharewski, T.R., 2017. Lipidomic Evaluation of Aryl Hydrocarbon Receptor-Mediated Hepatic Steatosis in Male and Female Mice Elicited by 2,3,7,8-Tetrachlorodibenzo-pdioxin. Chem. Res. Toxicol. 30, 1060-1075. https://doi.org/10.1021/acs.chemrestox.6b00430

Neuschwander-Tetri, B.A., 2010. Hepatic lipotoxicity and the pathogenesis of nonalcoholic steatohepatitis: The central role of nontriglyceride fatty acid metabolites. Hepatology 52, 774-788. https://doi.org/10.1002/hep.23719

O'Neill, L.A.J., Artyomov, M.N., 2019. Itaconate: the poster child of metabolic reprogramming in macrophage function. Nat. Rev. Immunol. 19, 273-281. https://doi.org/10.1038/s41577-019-0128-5

Oliver, R.M., 1975. Toxic effects of 2,3,7,8 tetrachlorodibenzo 1,4 dioxin in laboratory workers. Br. J. Ind. Med. 32, 49-53. https://doi.org/10.1136/oem.32.1.49

Otzen, C., Bardl, B., Jacobsen, I.D., Nett, M., Brock, M., 2014. Candida albicans utilizes a modified $\beta$-oxidation pathway for the degradation of toxic propionyl-CoA. J. Biol. Chem. 289, 8151-8169. https://doi.org/10.1074/jbc.M113.517672

Päpke, O., 1998. PCDD/PCDF: Human background data for Germany, a 10-year experience. Environ. Health Perspect. 106, 723-731. https://doi.org/10.1289/ehp.98106723

Pelclovä, D., Urban, P., Preiss, J., Lukää, E., Fenclovä, Z., Navrätil, T., Dubskä, Z., Senholdovä, Z., 2006. Adverse Health Effects in Humans Exposed to TCDD. Rev. Environ. Health 21, 119-138.

Peters, H., Ferdinandusse, S., Ruiter, J.P., Wanders, R.J.A., Boneh, A., Pitt, J., 2015. Metabolite studies in $\mathrm{HIBCH}$ and ECHS1 defects: Implications for screening. Mol. Genet. Metab. 115, $168-173$. https://doi.org/10.1016/j.ymgme.2015.06.008

Polyzos, S.A., Kang, E.S., Boutari, C., Rhee, E.J., Mantzoros, C.S., 2020. Current and emerging pharmacological options for the treatment of nonalcoholic steatohepatitis. Metabolism. 111, 154203. https://doi.org/10.1016/j.metabol.2020.154203

Quinlan, A.R., Hall, I.M., 2010. BEDTools: A flexible suite of utilities for comparing genomic features. Bioinformatics 26, 841-842. https://doi.org/10.1093/bioinformatics/btq033

Rives, C., Fougerat, A., Ellero-Simatos, S., Loiseau, N., Guillou, H., Gamet-Payrastre, L., Wahli, W., 2020. Oxidative stress in NAFLD: Role of nutrients and food contaminants. Biomolecules 10, 1702. https://doi.org/10.3390/biom10121702

Rowlands, J.C., Budinsky, R., Gollapudi, B., Novak, R., Abdelmegeed, M., Cukovic, D., Dombkowski, A., 2011. Transcriptional profiles induced by the Aryl Hydrocarbon Receptor agonists 2,3,7,8-tetrachlorodibenzo-pdioxin, 2,3,7,8-tetrachlorodibenzofuran and 2,3,4,7,8-pentachlorodibenzofuran in primary rat hepatocytes. Chemosphere 85, 232-238. https://doi.org/10.1016/j.chemosphere.2011.06.026

Ruetz, M., Campanello, G.C., Purchal, M., Shen, H., McDevitt, L., Gouda, H., Wakabayashi, S., Zhu, J., Rubin, E.J., Warncke, K., Mootha, V.K., Koutmos, M., Banerjee, R., 2019. Itaconyl-CoA forms a stable biradical in methylmalonyl-CoA mutase and derails its activity and repair. Science (80-. ). 366, 589-593. https://doi.org/10.1126/science.aay0934

Ruiz-Aracama, A., Peijnenburg, A., Kleinjans, J., Jennen, D., van Delft, J., Hellfrisch, C., Lommen, A., 2011. An untargeted multi-technique metabolomics approach to studying intracellular metabolites of HepG2 cells exposed to 2,3,7,8-tetrachlorodibenzo-p-dioxin. BMC Genomics 12, 251. https://doi.org/10.1186/1471-2164-12-251

Safe, S., 1990. Polychlorinated biphenyls (PCBs), dibenzo-p-dioxins (PCDDs), dibenzofurans (PCDFs), and related compounds: Environmental and mechanistic considerations which support the development of 
bioRxiv preprint doi: $\mathrm{https} / /$ doi.org/10.1101/2021.03.24.436837; this version posted March 25,2021 . The copyright holder for this preprint (which was not certified by peer review) is the author/funder, who has granted bioRxiv a license to display the preprint in perpetuity. It is made available under aCC-BY-ND 4.0 International license.

toxic equivalency factors (TEFs). Crit. Rev. Toxicol. 21, 51-88. https://doi.org/10.3109/10408449009089873

Sato, K., Nishina, Y., Setoyama, C., Miura, R., Shiga, K., 1999. Unusually high standard redox potential of acrylyl-CoA/propionyl-CoA couple among enoyl-CoA/acyl-CoA couples: A reason for the distinct metabolic pathway of propionyl-CoA from longer acyl-CoAs. J. Biochem. 126, 668-675. https://doi.org/10.1093/oxfordjournals.jbchem.a022501

Sayiner, M., Lam, B., Golabi, P., Younossi, Z, M., 2018. Advances and challenges in the management of advanced fibrosis in nonalcoholic steatohepatitis. Ther. Adv. Vaccines 11, 1-12. https://doi.org/10.1177/https

Schjonsby, H., 1989. Vitamin B12 absorption and malabsorption. Gut 30, 1686-1691. https://doi.org/10.1136/gut.30.12.1686

Schwab, M.A., Sauer, S.W., Okun, J.G., Nijtmans, L.G.J., Rodenburg, R.J.T., Van Den Heuvel, L.P., Dröse, S., Brandt, U., Hoffmann, G.F., Ter Laak, H., Kölker, S., Smeitink, J.A.M., 2006. Secondary mitochondrial dysfunction in propionic aciduria: A pathogenic role for endogenous mitochondrial toxins. Biochem. J. 398, 107-112. https://doi.org/10.1042/BJ20060221

Shelton, A.N., Seth, E.C., Mok, K.C., Han, A.W., Jackson, S.N., Haft, D.R., Taga, M.E., 2018. Uneven distribution of cobamide biosynthesis and dependence in bacteria predicted by comparative genomics. ISME J. 13, 789-804. https://doi.org/10.1038/s41396-018-0304-9

Shen, H., Campanello, G.C., Flicker, D., Grabarek, Z., Hu, J., Luo, C., Banerjee, R., Mootha, V.K., 2017. The Human Knockout Gene CLYBL Connects Itaconate to Vitamin B12. Cell 171, 771-782.e11. https://doi.org/10.1016/j.cell.2017.09.051

Shimomura, Y., Murakami, T., Fujitsuka, N., Nakai, N., Sato, Y., Sugiyama, S., Shimomura, N., Irwin, J., Hawes, J.W., Harris, R.A., 1994. Purification and partial characterization of 3-hydroxyisobutyryl-coenzyme A hydrolase of rat liver. J. Biol. Chem. 269, 14248-14253. https://doi.org/10.1016/S0021-9258(17)367819

Singh, V. V., Toskes, P.P., 2004. Small bowel bacterial overgrowth: Presentation, diagnosis, and treatment. Curr. Treat. Options Gastroenterol. 7, 19-28. https://doi.org/10.1007/s11938-004-0022-4

Sorg, O., Zennegg, M., Schmid, P., Fedosyuk, R., Valikhnovskyi, R., Gaide, O., Kniazevych, V., Saurat, J.H., 2009. 2,3,7,8-tetrachlorodibenzo-p-dioxin (TCDD) poisoning in Victor Yushchenko: identification and measurement of TCDD metabolites. Lancet 374, 1179-1185. https://doi.org/10.1016/S01406736(09)60912-0

Strelko, C.L., Lu, W., Dufort, F.J., Seyfried, T.N., Chiles, T.C., Rabinowitz, J.D., Roberts, M.F., 2011. Itaconic acid is a mammalian metabolite induced during macrophage activation. J. Am. Chem. Soc. 133, 1638616389. https://doi.org/10.1021/ja2070889.Itaconic

Sweeney, M.H., Calvert, G.M., Egeland, G.A., Fingerhut, M.A., Halperin, W.E., Piacitelli, L.A., 1997. Review and update of the results of the NIOSH medical study of workers exposed to chemicals contaminated with 2,3,7,8-tetrachlorodibenzodioxin. Teratog. Carcinog. Mutagen. 17, 241-247. https://doi.org/10.1002/(SICI)1520-6866(1997)17:4/5<241::AID-TCM6>3.0.CO;2-I

Taylor, K., Anderson, H., Birnbaum, L., Blystone, C., Devito, M., Jacobs, D., Kohrle, J., Lee, D.H., Rylander, L., Rignell-Hydbom, A., Tornero-Velez, R., Turyk, M.E., Boyles, A., Thayer, K.A., Lind, L., 2013. Evaluation of the association between persistent organic pollutants (POPS) and diabetes in epidemiological studies: A National Toxicology Program Workshop Review. Environ. Health Perspect. 121, 774-783.

Tilg, H., Moschen, A.R., 2010. Evolution of inflammation in nonalcoholic fatty liver disease: The multiple parallel hits hypothesis. Hepatology 52, 1836-1846. https://doi.org/10.1002/hep.24001

Vezina, C.M., Walker, N.J., Olson, J.R., 2004. Subchronic exposure to TCDD, PeCDF, PCB126, and PCB153: Effect on hepatic gene expression. Environ. Health Perspect. 112, 1636-1644. https://doi.org/10.1289/txg.7253 
Wahlang, B., Beier, J.I., Clair, H.B., Bellis-Jones, H.J., Falkner, K.C., McClain, C.J., Cave, M.C., 2013. Toxicant-associated Steatohepatitis. $\quad$ Toxicol. $\quad$ Pathol. 343-360. https://doi.org/10.1177/0192623312468517

Wahlang, B., Jin, J., Beier, J.I., Hardesty, J.E., Daly, E.F., Schnegelberger, R.D., Falkner, K.C., Prough, R.A., Kirpich, I.A., Cave, M.C., 2019. Mechanisms of Environmental Contributions to Fatty Liver Disease. Curr. Environ. Heal. reports 6, 80-94. https://doi.org/10.1007/s40572-019-00232-w

Warner, M., Mocarelli, P., Brambilla, P., Wesselink, A., Samuels, S., Signorini, S., Eskenazi, B., 2013. Diabetes, metabolic syndrome, and obesity in relation to serum dioxin concentrations: The Seveso Women's Health Study. Environ. Health Perspect. 121, 906-911. https://doi.org/10.1289/ehp.1206113

Warner, M., Rauch, S., Ames, J., Mocarelli, P., Brambilla, P., Signorini, S., Eskenazi, B., 2019. In utero dioxin exposure and cardiometabolic risk in the Seveso Second Generation Study. Int. J. Obes. 43, 2233-2243. https://doi.org/10.1038/s41366-018-0306-8

Watkins, D., Rosenblatt, D.S., 2011. Inborn errors of cobalamin absorption and metabolism. Am. J. Med. Genet. Part C Semin. Med. Genet. 157, 33-44. https://doi.org/10.1002/ajmg.c.30288

Watkins, D., Schwartzentruber, J.A., Ganesh, J., Orange, J.S., Kaplan, B.S., Nunez, L.D., Majewski, J., Rosenblatt, D.S., 2011. Novel inborn error of folate metabolism: Identification by exome capture and sequencing of mutations in the MTHFD1 gene in a single proband. J. Med. Genet. 48, 590-592. https://doi.org/10.1136/jmedgenet-2011-100286

Wishart, D.S., Feunang, Y.D., Marcu, A., Guo, A.C., Liang, K., Vázquez-Fresno, R., Sajed, T., Johnson, D., Li, C., Karu, N., Sayeeda, Z., Lo, E., Assempour, N., Berjanskii, M., Singhal, S., Arndt, D., Liang, Y., Badran, H., Grant, J., Serra-Cayuela, A., Liu, Y., Mandal, R., Neveu, V., Pon, A., Knox, C., Wilson, M., Manach, C., Scalbert, A., 2018. HMDB 4.0: The human metabolome database for 2018. Nucleic Acids Res. 46, D608-D617. https://doi.org/10.1093/nar/gkx1089

Wolfe, W.H., Michalek, J.E., Miner, J.C., Pirkle, J.L., Caudill, S.P., Patterson, D.G., Needham, L.L., 1994. Determinants of TCDD half-life in veterans of operation ranch hand. J. Toxicol. Environ. Health 41, 481488. https://doi.org/10.1080/15287399409531858

Wong, R.J., Aguilar, M., Cheung, R., Perumpail, R.B., Harrison, S.A., Younossi, Z.M., Ahmed, A., 2015. Nonalcoholic steatohepatitis is the second leading etiology of liver disease among adults awaiting liver transplantation in the United States. Gastroenterology 148, 547-555. https://doi.org/10.1053/j.gastro.2014.11.039

Wong, R.J., Singal, A.K., 2020. Trends in Liver Disease Etiology Among Adults Awaiting Liver Transplantation in the United States, 2014-2019. JAMA Netw. open 3, e1920294. https://doi.org/10.1001/jamanetworkopen.2019.20294

Wree, A., Broderick, L., Canbay, A., Hoffman, H.M., Feldstein, A.E., 2013. From NAFLD to NASH to cirrhosisnew insights into disease mechanisms. Nat. Rev. Gastroenterol. Hepatol. 10, 627-636. https://doi.org/10.1038/nrgastro.2013.149

Zaslona, Z., O’Neill, L.A.J., 2020. Cytokine-like Roles for Metabolites in Immunity. Mol. Cell 78, 814-823. https://doi.org/10.1016/j.molcel.2020.04.002

Zhang, L., Hatzakis, E., Nichols, R.G., Hao, R., Correll, J., Smith, P.B., Chiaro, C.R., Perdew, G.H., Patterson, A.D., 2015. Metabolomics Reveals that Aryl Hydrocarbon Receptor Activation by Environmental Chemicals Induces Systemic Metabolic Dysfunction in Mice. Environ. Sci. Technol. 49, 8067-8077. https://doi.org/10.1021/acs.est.5b01389 
Table 1. Metabolite fold changes in comparison to vehicle in liver extracts ( $n=4-5, \pm$ S.E.) assessed by untargeted liquid chromatography tandem mass spectrometry. Mice were orally gavaged every 4 days for 28 days with TCDD (or sesame oil vehicle). Asterisk $\left(^{*}\right)$ denotes significance $(p \leq 0.05)$ determined by one-way ANOVA with Dunnett's post-hoc testing. Scores ranging from 30 - 40 are based on mass error and isotope distribution similarity, while score $>40$ are based on mass error, isotope distribution and fragmentation score. All identified compounds have a score distribution averaging 35.

\begin{tabular}{|c|c|c|c|c|c|c|c|c|}
\hline \multirow{2}{*}{ Compound ID } & \multirow{2}{*}{ Annotation } & \multirow{2}{*}{ Score } & \multirow{2}{*}{$\begin{array}{l}\text { Retention } \\
\text { Time } \\
\text { (min) }\end{array}$} & \multicolumn{5}{|c|}{ Fold-Change (TCDD vs Vehicle) } \\
\hline & & & & $0.3 \mu \mathrm{g} / \mathrm{kg}$ & $1 \mu \mathrm{g} / \mathrm{kg}$ & $3 \mu \mathrm{g} / \mathrm{kg}$ & $10 \mu \mathrm{g} / \mathrm{kg}$ & $30 \mu \mathrm{g} / \mathrm{kg}$ \\
\hline HMDB01275 & Propionyl-CoA & 42.4 & 6.84 & $1.56 \pm 0.23$ & $0.55 \pm 0.14$ & $0.89 \pm 0.16$ & $0.11 \pm 0.07^{*}$ & $0.19 \pm 0.07^{*}$ \\
\hline HMDB02307 & Acrylyl-CoA & 35.3 & 8.05 & $0.83 \pm 0.04$ & $0.88 \pm 0.05$ & $31.05 \pm 30.15$ & $141.44 \pm 5.65^{\star}$ & $161.69 \pm 5.84^{*}$ \\
\hline HMDB06807 & $\begin{array}{c}\text { 3-Hydroxypropionyl- } \\
\text { CoA }\end{array}$ & 37.1 & 2.69 & $1.43 \pm 0.07$ & $1.78 \pm 0.25$ & $1.73 \pm 0.23$ & $1.63 \pm 0.36$ & $2.79 \pm 0.49^{\star}$ \\
\hline
\end{tabular}

Table 2. Metabolite fold changes in comparison to vehicle of hepatic metabolites associated with itaconate pathway assessed by untargeted liquid chromatography tandem mass spectrometry. Mice $(n=4-5, \pm S$.E. $)$ were orally gavaged every 4 days for 28 days with sesame oil vehicle or TCDD. Asterisk $\left(^{*}\right)$ denotes statistical significance $(p \leq 0.05)$ determined using a one-way ANOVA with Dunnett's post-hoc testing. Scores ranging from 30 - 40 are based on mass error and isotope distribution similarity, while score $>40$ are based on mass error, isotope distribution and fragmentation score. All identified compounds have a score distribution averaging $\sim 35$.

\begin{tabular}{|c|c|c|c|c|c|c|c|c|}
\hline \multirow{2}{*}{ Compound ID } & \multirow{2}{*}{ Description } & \multirow{2}{*}{ Score } & \multirow{2}{*}{$\begin{array}{c}\text { Retention } \\
\text { Time } \\
\text { (min) }\end{array}$} & \multicolumn{5}{|c|}{ Fold-Change (TCDD vs Vehicle) } \\
\hline & & & & $0.3 \mu \mathrm{g} / \mathrm{kg}$ & $1 \mu \mathrm{g} / \mathrm{kg}$ & $3 \mu \mathrm{g} / \mathrm{kg}$ & $10 \mu \mathrm{g} / \mathrm{kg}$ & $30 \mu \mathrm{g} / \mathrm{kg}$ \\
\hline HMDB03377 & Itaconyl-CoA & 44.7 & 2.65 & $0.68 \pm 0.09$ & $0.72 \pm 0.06$ & $0.76 \pm 0.07$ & $0.72 \pm 0.07$ & $0.18 \pm 0.06^{\star}$ \\
\hline HMDB06345 & Citramalyl-CoA & 47.4 & 5.27 & $0.58 \pm 0.03^{*}$ & $0.46 \pm 0.03^{*}$ & $0.34 \pm 0.03^{*}$ & $0.27 \pm 0.04^{*}$ & $0.05 \pm 0.02^{*}$ \\
\hline
\end{tabular}




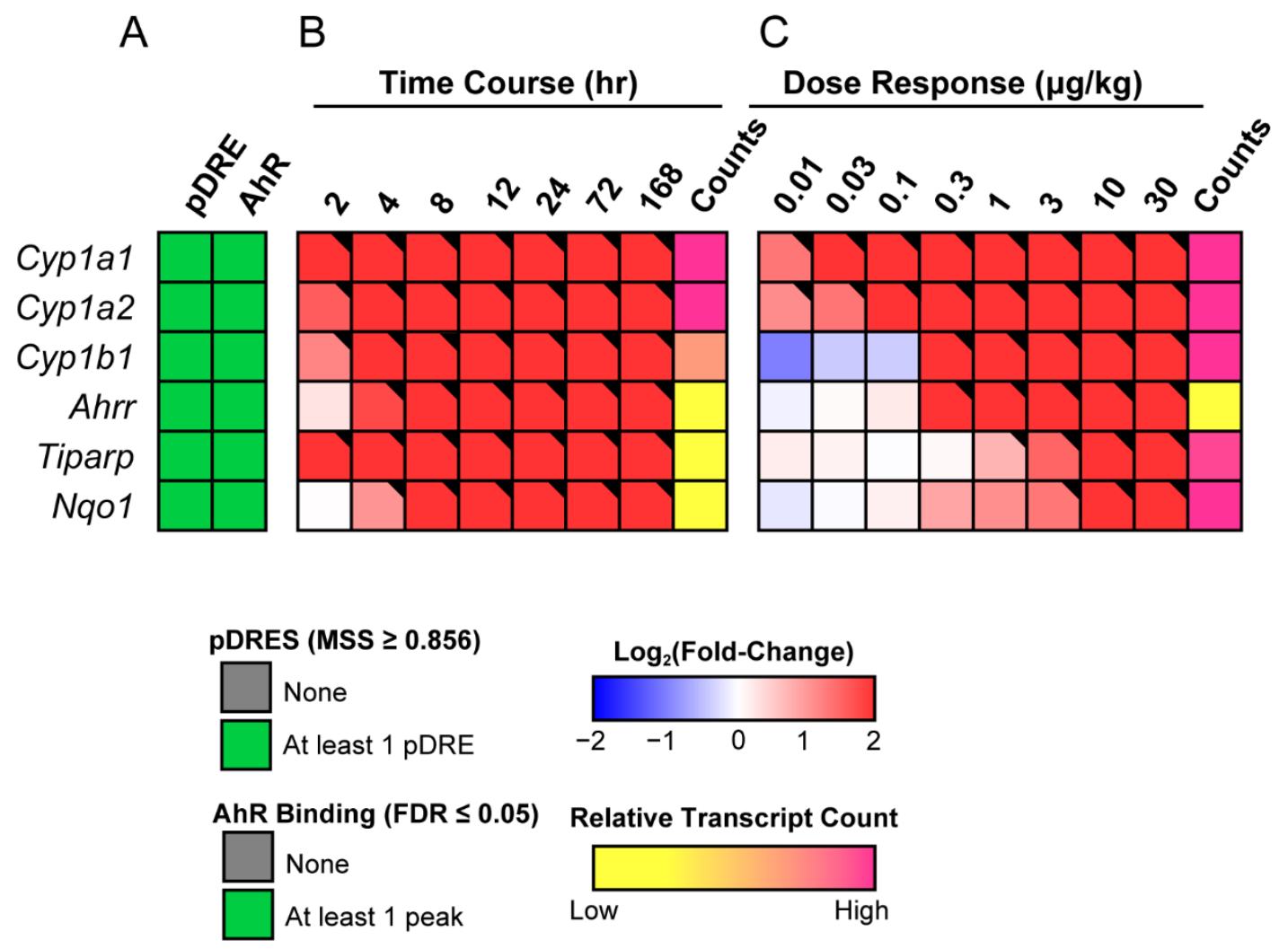

Figure 1. Effects of TCDD on the expression of AhR target genes. A) The presence of putative dioxin response elements (pDREs) and AhR genomic binding $2 \mathrm{hrs}$ after a single bolus dose of $30 \mu \mathrm{g} / \mathrm{kg}$ TCDD. B) Hepatic expression of AhR target genes assessed in a time course study. Male C57BL/6 mice $(n=3)$ were administered a single bolus dose of $30 \mu \mathrm{g} / \mathrm{kg}$ TCDD. Liver samples were collected at the corresponding time point. Color scale represents the $\log _{2}$ (fold change) for differential gene expression determined by RNA-Seq analysis. Counts represent the maximum number of raw aligned reads for any treatment group. Low counts $(<500$ reads) are denoted in yellow with high counts $(>10,000)$ in pink. C) Dose-dependent gene expression was assessed in mice $(n=3)$ following oral gavage with sesame oil vehicle or TCDD. Differential expression with a posterior probability $(\mathrm{P} 1(t))>0.80$ is indicated with a black triangle in the upper right tile corner. 


\section{A}

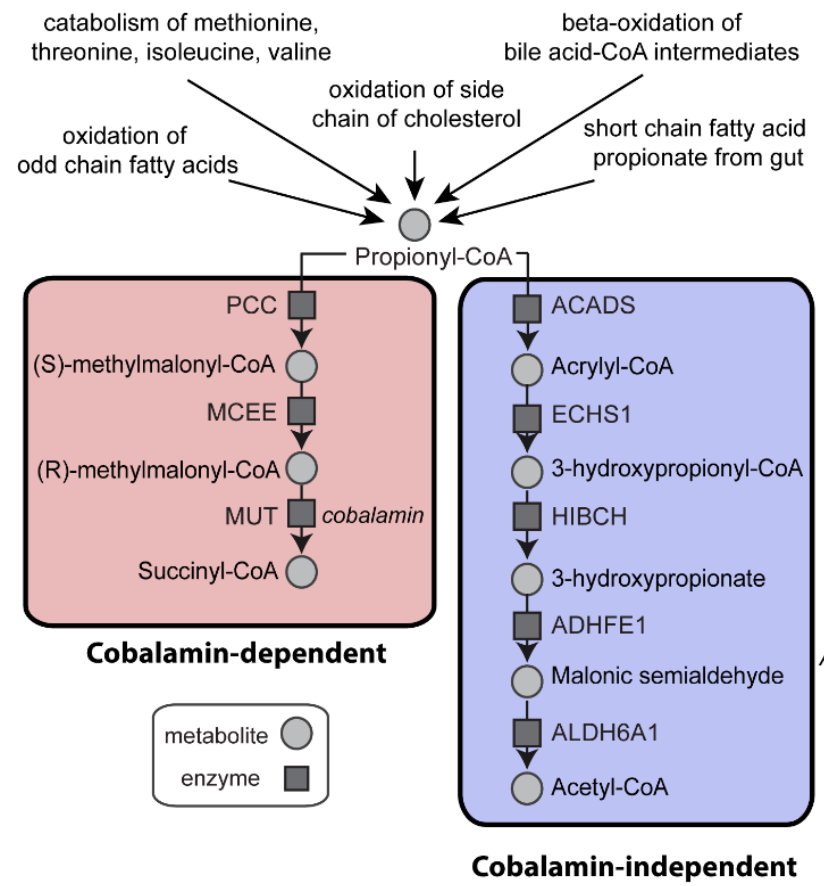

B

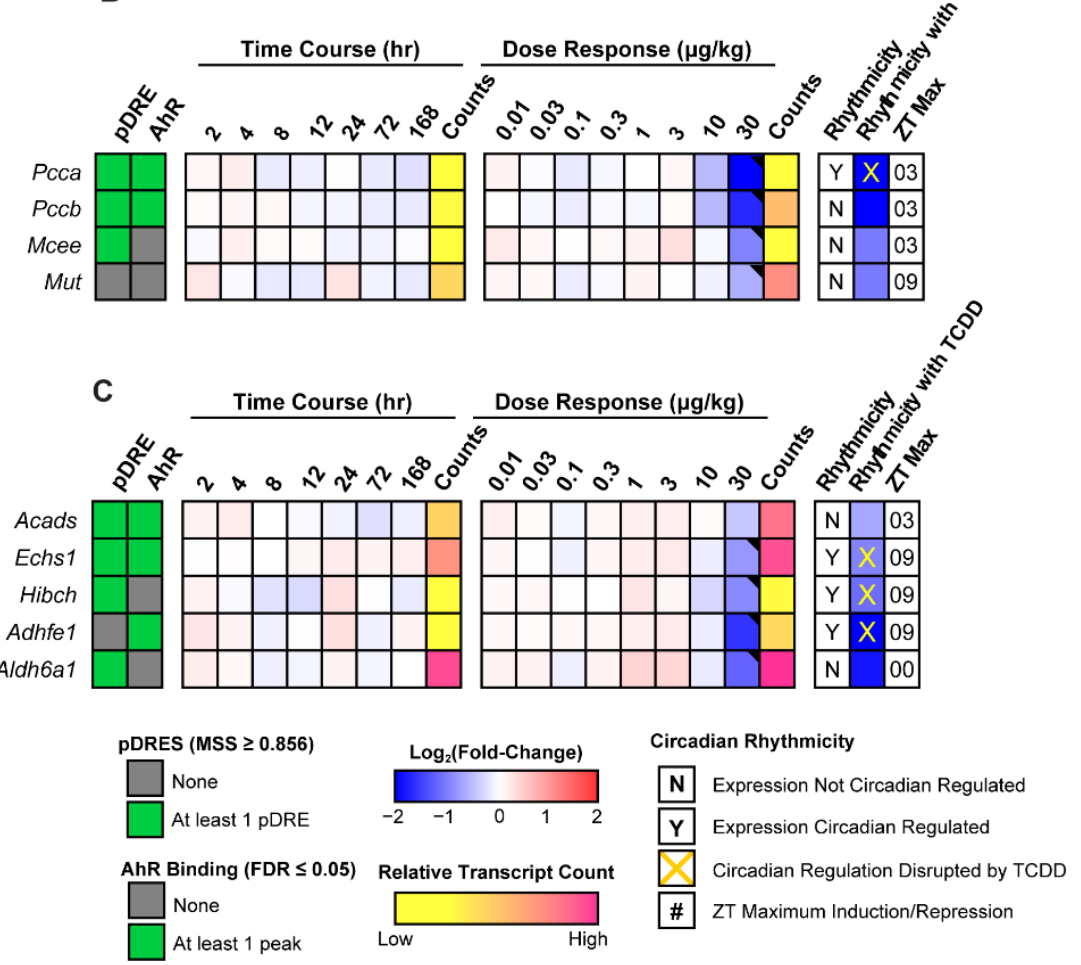

Figure 2. Effects of TCDD on the expression of genes associated with propionyl-CoA metabolism. A) Schematic pathway depicting enzymes and metabolites associated with propionyl-CoA metabolism via the cobalamin (Cbl)-dependent carboxylation pathway or the Cbl-independent $\beta$-oxidation-like pathway. B) Heatmap for genes associated with the propionyl-CoA canonical carboxylation pathway. C) Heatmap for genes associated with the Cbl-independent propionyl-CoA $\beta$-oxidation-like pathway. Hepatic expression of genes associated with propionyl-CoA was assessed in a time course- and dose-dependent manner. In time course study male C57BL/6 mice $(n=3)$ were administered a single bolus dose of $30 \mu \mathrm{g} / \mathrm{kg}$ TCDD, after which tissue was collected at the corresponding timepoint, while in dose-dependent study male C57BL/6 mice $(n=3)$ were orally gavaged with sesame oil vehicle or TCDD every 4 days for 28 days. The presence of putative dioxin response elements (pDREs) and AhR binding to the intragenic region represents as green boxes. Color scale represents the $\log _{2}$ (fold change) for differential gene expression determined by RNA-Seq analysis. Counts represents the maximum raw number of aligned reads to each transcript where a lower level of expression ( $\leq 500$ reads) is depicted in yellow and a higher level of expression $(\geq 10,000)$ is depicted in pink. Genes that are circadian regulated are denoted by "Y". Disruption of circadian rhythmicity following oral gavage with 30 $\mu \mathrm{g} / \mathrm{kg}$ TCDD every 4 days for 28 days is denoted by an orange ' $X$ '. The ZT with maximum induction/repression is shown for each gene. Differential expression with a posterior probability $(\mathrm{P} 1(t))>0.80$ is indicated with a black triangle in the upper right tile corner. 
A

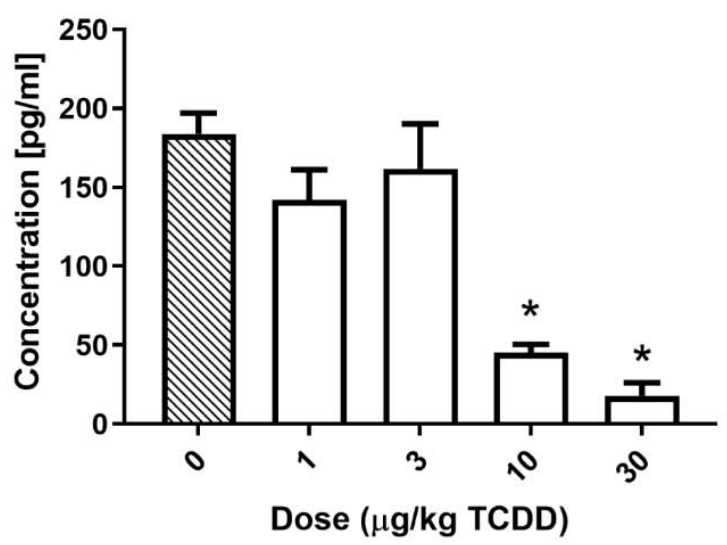

B

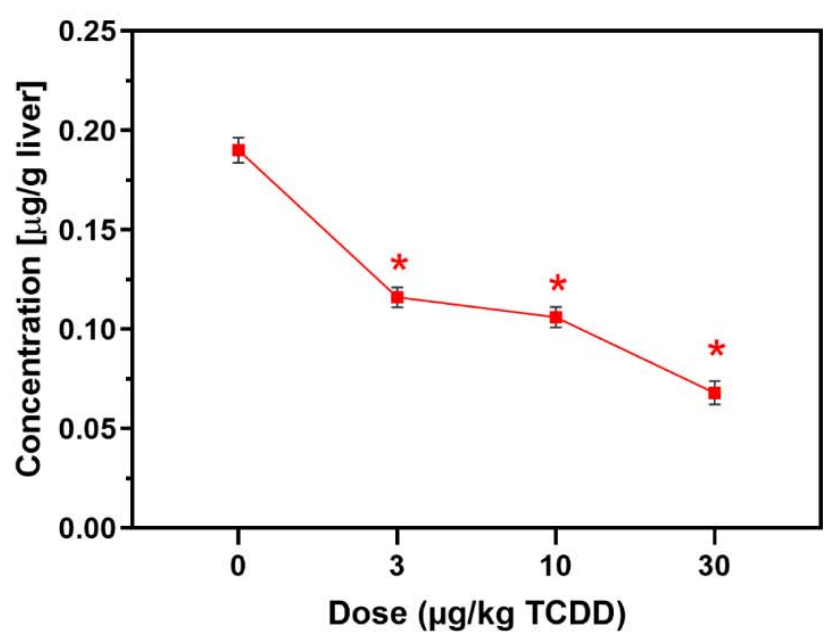

Figure 3. TCDD-elicited effects on A) serum cobalamin and B) hepatic cobalt levels. Male C57BL/6 mice were orally gavaged every four days with sesame oil vehicle or TCDD for 28 days $(n=4-5, \pm$ SEM). Serum cobalamin levels were determined by an ELISA assay. Cobalt levels in liver extracts were measured by inductively coupled plasma mass spectrometry (ICP-MS). Asterisk $\left({ }^{*}\right)$ denotes $p<0.05$ determined by oneway ANOVA with a Dunnett's post-hoc test. 
bioRxiv preprint doi: https://doi.org/10.1101/2021.03 24.436837; this version posted March 25,2021 . The copyright holder for this preprint (which was not certified by peer review) is the author/funder, who has granted bioRxiv a license to display the preprint in perpetuity. It is made available under aCC-BY-ND 4.0 International license.

A

\section{Gut lumen}

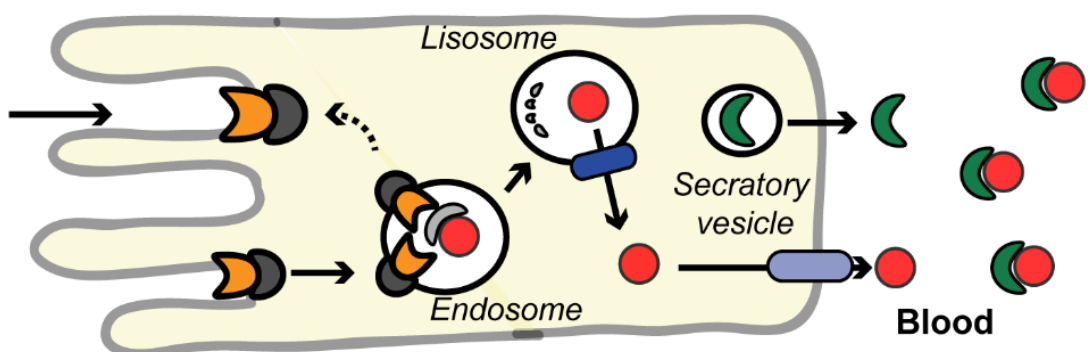

\footnotetext{
(-Intrinsic Factor (Cblif)

- cobalamin 2 -cubilin (Cubn)

D-amnionless (Amn)

- lysosomal cobalamin transporter (Lmbrd1) $\}$-transcobalamin $(T c n 2)$

-ATP Binding Cassette Subfamily C Member 1 (Abcc1)
}

B

DUODENUM

JEJUNUM
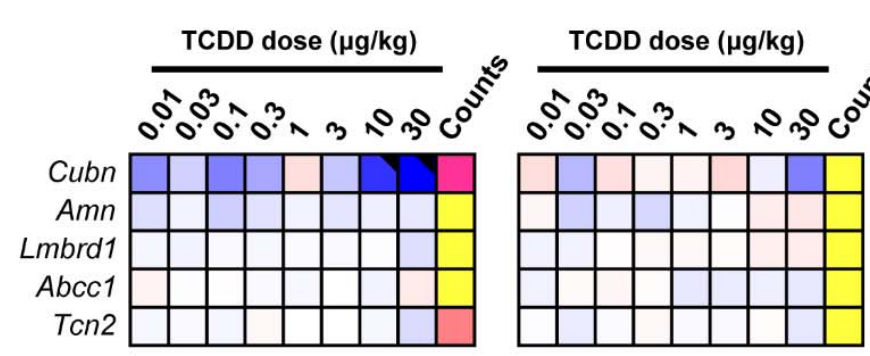

ILEUM (PROXIMAL)

ILEUM (DISTAL)

COLON

TCDD dose $(\mu \mathrm{g} / \mathrm{kg}) \quad$ TCDD dose $(\mu \mathrm{g} / \mathrm{kg})$
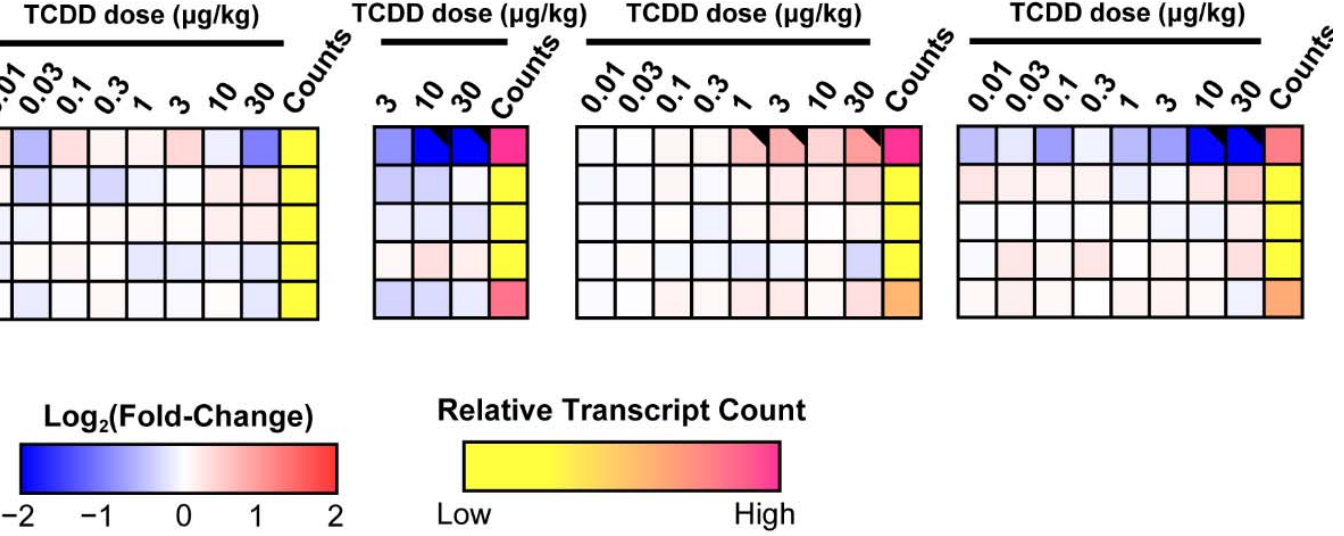

Relative Transcript Count

Figure 4. TCDD-elicited effects on gene expression associated with the intestinal absorption and processing of cobalamin (Cbl). A) Schematic overview of enterocyte uptake and processing of Cbl. B) Dose-dependent effects of TCDD on duodenal, jejunum, ileal (proximal and distal), and colonic gene expression associated with $\mathrm{Cbl}$ absorption and processing. Male C57BL/6 mice $(\mathrm{n}=3)$ were orally gavaged with sesame oil vehicle or TCDD every 4 days for 28 days. Color scale represents the $\log _{2}$ (fold change) for differential gene expression determined by RNA-Seq analysis. Counts represents the maximum raw number of aligned reads to each transcript where a lower level of expression ( $\leq 500$ reads) is depicted in yellow and a higher level of expression $(\geq 10,000)$ is depicted in pink. Differential expression with a posterior probability $(\mathrm{P} 1(t))>0.80$ is indicated with a black triangle in the upper right tile corner. 


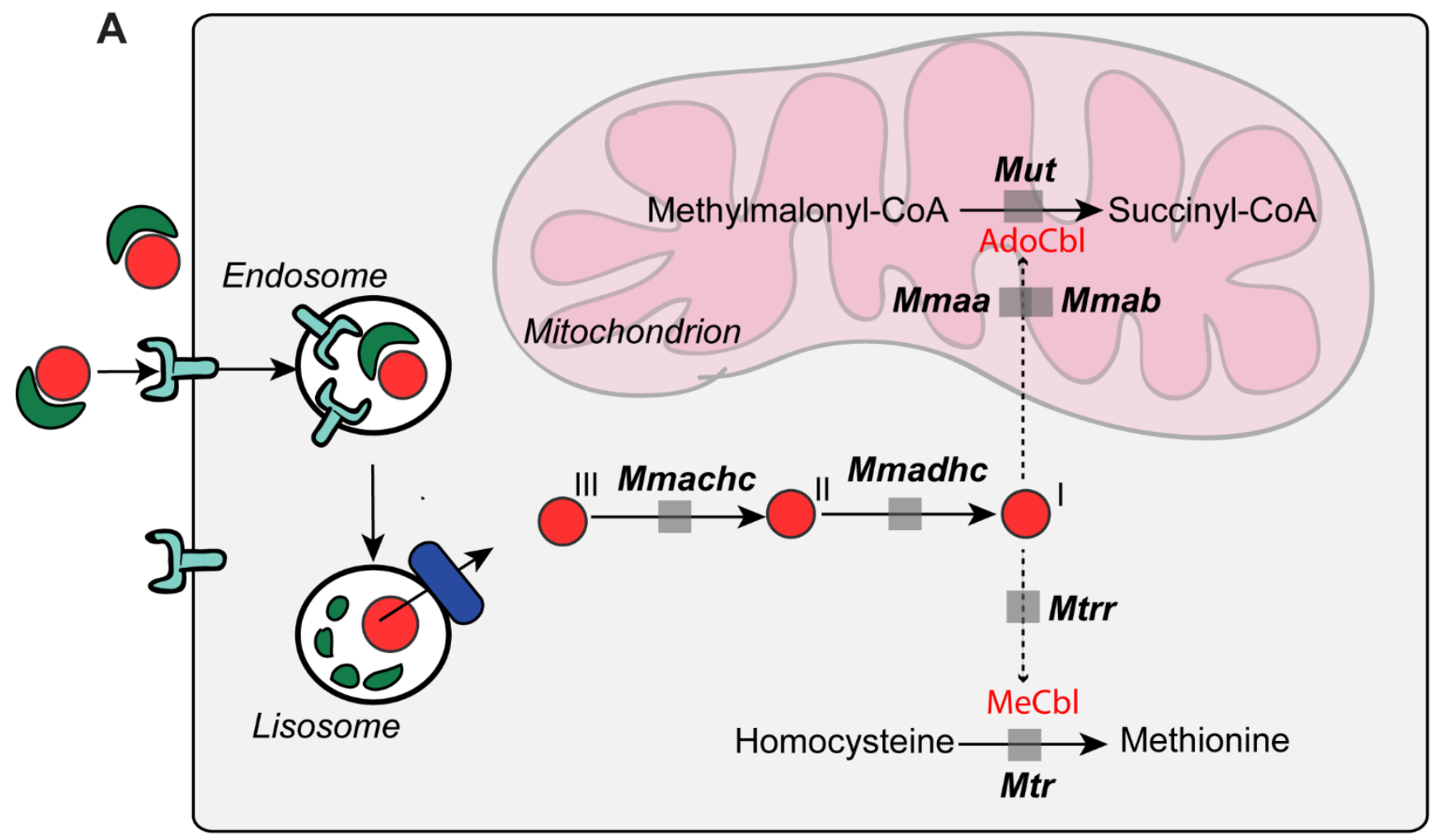

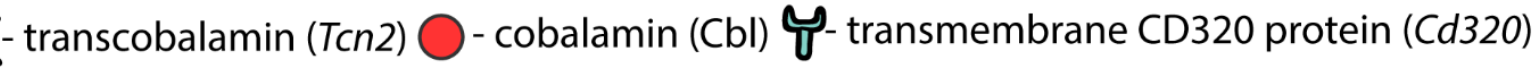
$\square$ - lysosomal cobalamin transporter (Lmbrd1) - gen

B
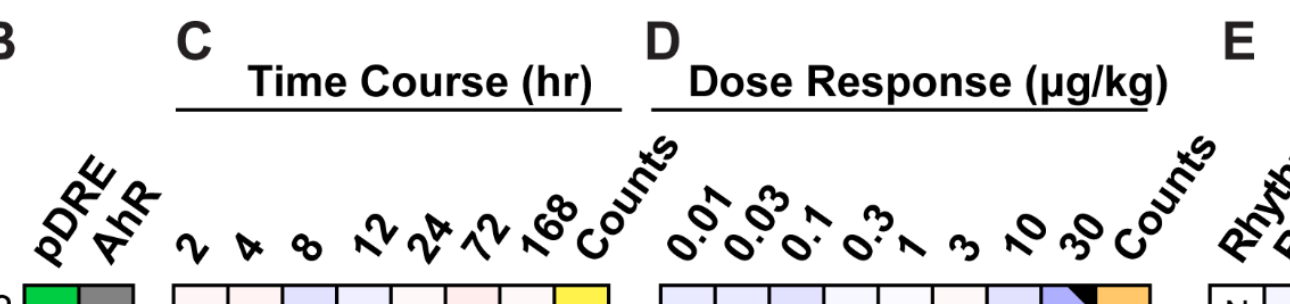

Tcn2
Cd320
Mmachc
Mmadhc
Mmaa
Mmab
Mtrr
Mtr
Mut
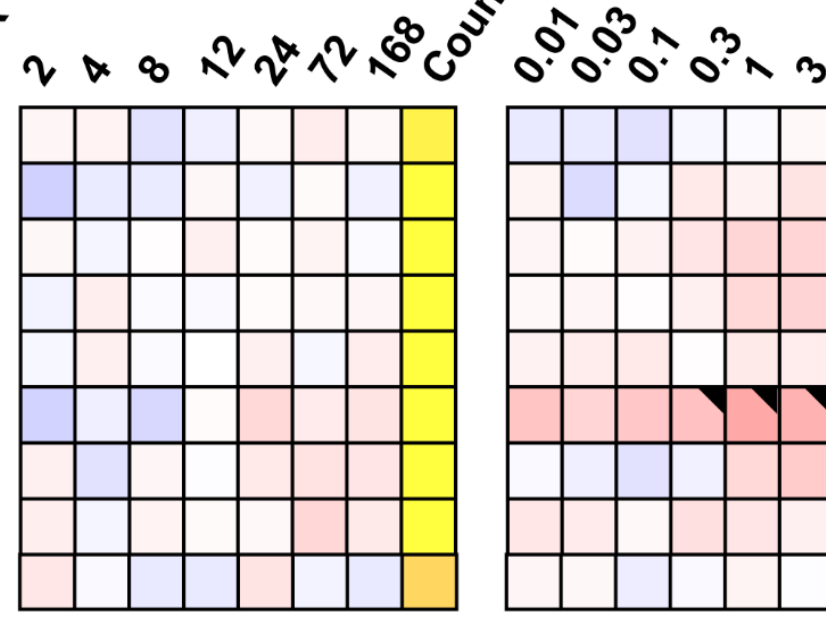

이
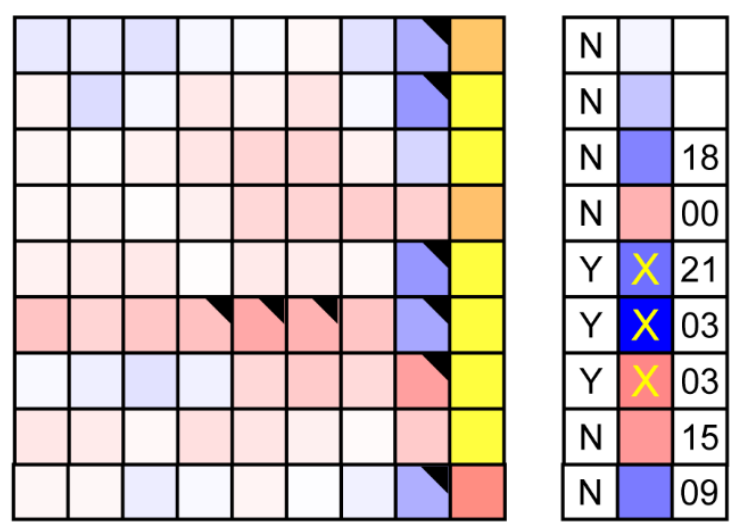

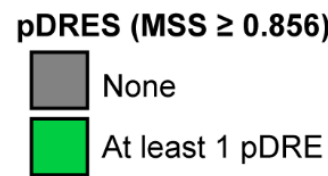

AhR Binding (FDR $\leq 0.05$ )

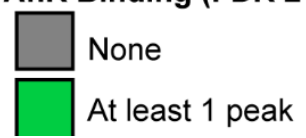

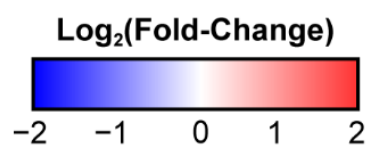

Relative Transcript Count

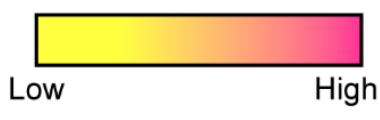

Circadian Rhythmicity

N Expression Not Circadian Regulated

Y Expression Circadian Regulated

Circadian Regulation Disrupted by TCDD

\# ZT Maximum Induction/Repression 
Figure 5. TCDD-elicited effects on gene expression involved in hepatic uptake, metabolism and trafficking of cobalamin (Cbl). A) Overview of Cbl uptake, metabolism and trafficking in the mouse liver. B) The presence of putative dioxin response elements (pDREs) and AhR genomic binding 2 hrs after a single bolus dose of $30 \mu \mathrm{g} / \mathrm{kg}$ TCDD. C) Hepatic expression of genes associated with Cbl uptake, metabolism and trafficking in a time course study. Male C57BL/6 mice $(n=3)$ were administered a single bolus dose of 30 $\mu \mathrm{g} / \mathrm{kg}$ TCDD. Liver samples were collected at the corresponding time point. Color scale represents the $\log _{2}$ (fold change) for differential gene expression determined by RNA-Seq analysis. Counts represent the maximum number of raw aligned reads for any treatment group. Low counts ( $<500$ reads) are denoted in yellow with high counts $(>10,000)$ in pink. D) Dose-dependent gene expression was assessed in mice $(n=3)$ following oral gavage with sesame oil vehicle or TCDD. E) Circadian regulated genes are denoted with a "Y". An orange ' $X$ ' indicates disrupted diurnal rhythm following oral gavage with $30 \mu g / k g$ TCDD every 4 days for 28 days. ZT indicates statistically significant $(\mathrm{P} 1(t)>0.8)$ time of maximum gene induction/repression. Differential expression with a posterior probability $(P 1(t))>0.80$ is indicated with a black triangle in the upper right tile corner. 
A

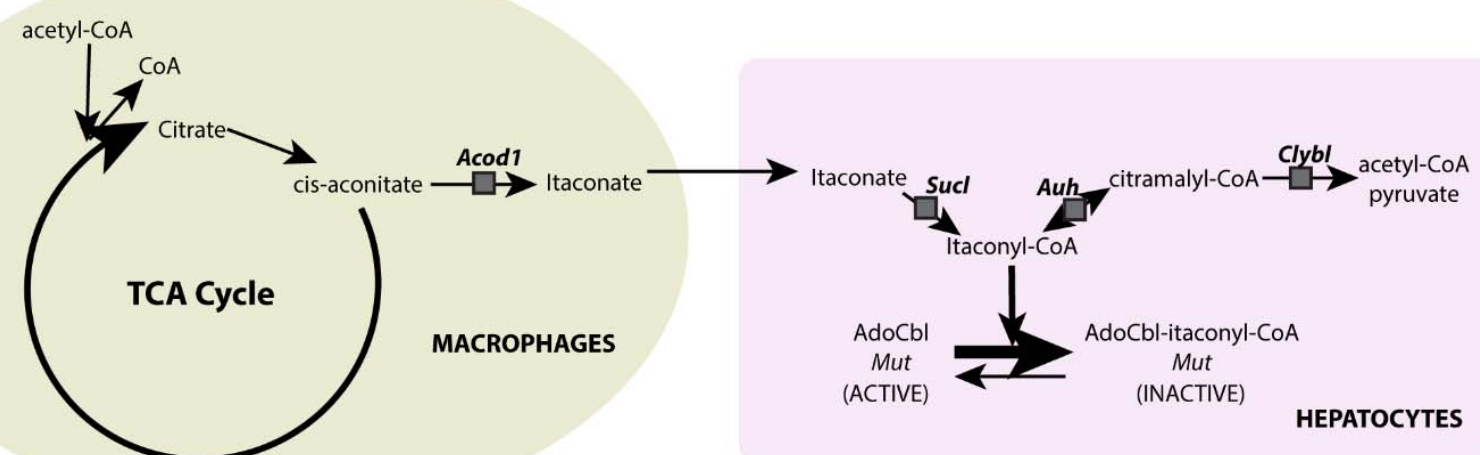

Time course

B

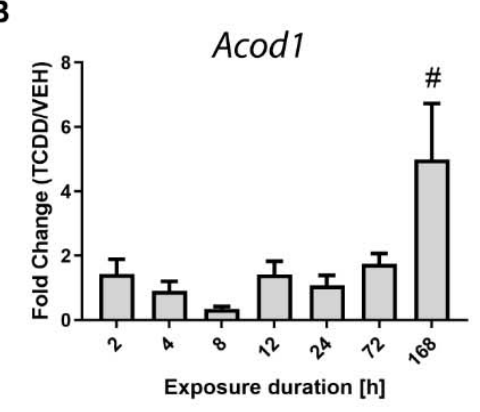

E

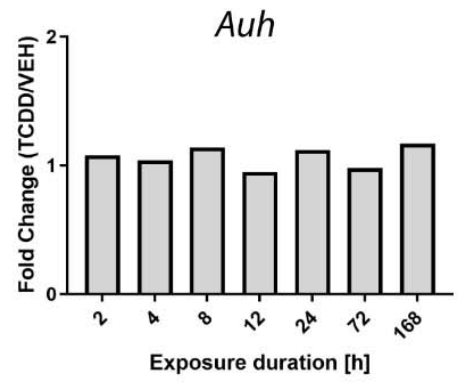

H

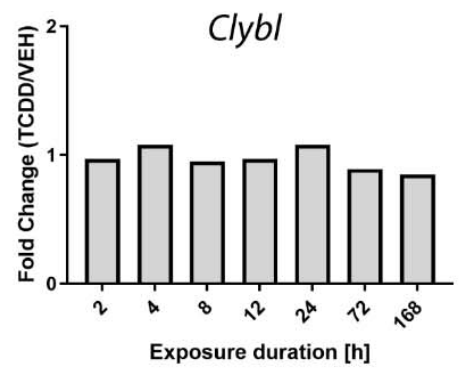

Dose response

C

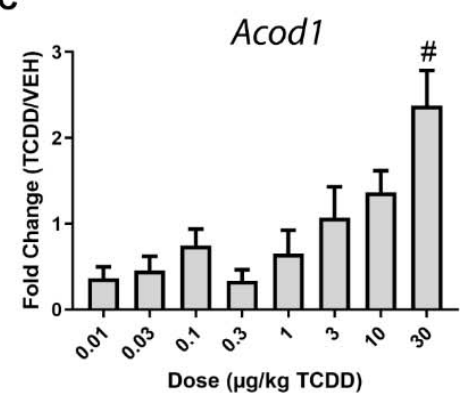

$\mathbf{F}$

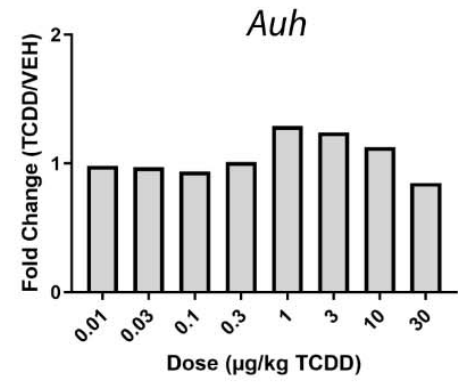

I

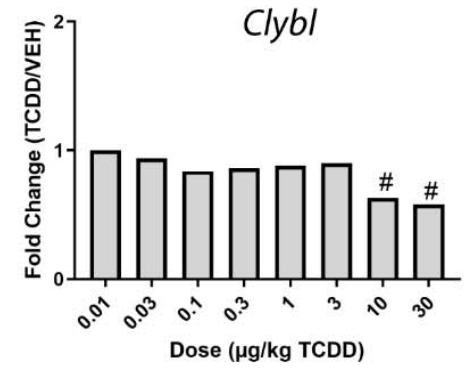

Diurnal rhythmicity

D
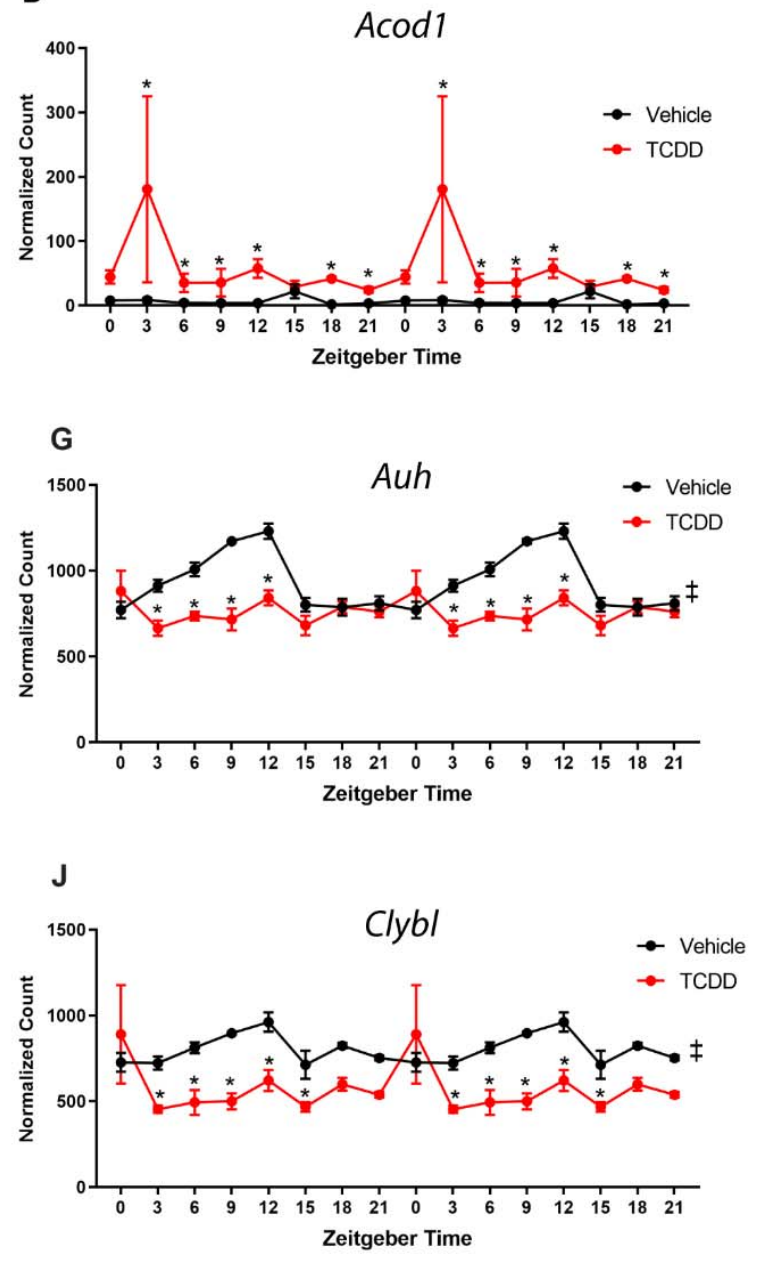

$\mathbf{K}$

Time Course (hr)

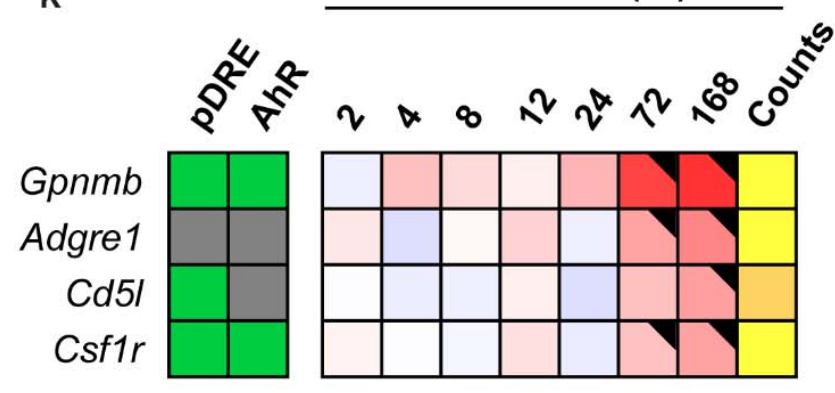

pDRES (MSS $\geq 0.856$ )
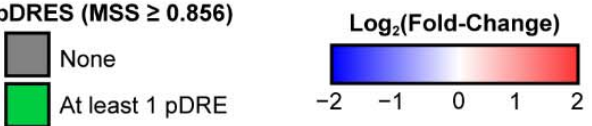

AhR Binding (FDR $\leq 0.05)$

None

At least 1 peak
Relative Transcript Count

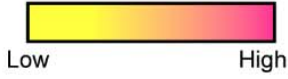


Figure 6. TCDD-elicited effects on the genes involved in the itaconate pathway. A) Schematic overview of the pathway. Hepatic expression of (B) Acod1, (E) Auh, (H) Clyb/ was determined by qRT-PCR (Acod1) or RNA-Seq (Auh, Clybl) for time-course analysis after a single bolus oral gavage of $30 \mu \mathrm{g} / \mathrm{kg}$ TCDD $(\mathrm{n}=3-5)$. Dose dependent expression of (C) Acod1, (F) Auh, (I) Clybl determined by qRT-PCR (Acod1) or RNA-Seq (Auh, Clybl) following treated with TCDD. Male C57BL/6 mice $(n=3-4)$ were orally gavaged with sesame oil vehicle or TCDD $(0.01-30 \mu \mathrm{g} / \mathrm{kg})$ every 4 days for 28 days. Pound sign (\#) denotes $\mathrm{p}<0.05$ determined by one-way ANOVA with a Dunnett's post-hoc test. The effect of TCDD on the diurnal rhythmicity of (D) Acod1 (G) Auh, (J) Clyb/ in male C57BL/6 mice following oral gavage with sesame oil vehicle or 30 $\square \mu \mathrm{g} / \mathrm{kg}$ TCDD every 4 days for 28 days. Posterior probabilities $\left({ }^{*} \mathrm{P} 1(\mathrm{t}) \geq 0.80\right)$ comparing vehicle and TCDD were determined using an empirical Bayes method. Diurnal rhythmicity was assessed using JTK_CYCLE ( $¥$ indicates $\mathrm{q} \leq 0.1$ ). Data are double-plotted along the $\mathrm{x}$-axis to better visualize rhythmic pattern. K) Time dependent hepatic expression of macrophages markers. Male C57BL/6 mice $(n=3)$ were administered a single bolus dose of $30 \mu \mathrm{g} / \mathrm{kg}$ TCDD. Liver samples were collected at the corresponding time point. The presence of putative dioxin response elements (pDREs) and AhR enrichment are represented as green boxes. Color scale represents the log2(fold change) for differential gene expression determined by RNASeq analysis. Counts represents the maximum raw number of aligned reads to each transcript where a lower level of expression ( $\leq 500$ reads) is depicted in yellow and a higher level of expression $(\geq 10,000)$ is depicted in pink. Differential expression with a posterior probability $(\mathrm{P} 1(t))>0.80$ is indicated with a black triangle in the upper right tile corner. 